\title{
Chemoreception in the context of the general biology of ROS
}

\author{
C. Gonzalez*, M.T. Agapito, A. Rocher, M.C. Gonzalez-Martin, V. Vega-Agapito, \\ A. Gomez-Niño, R. Rigual, J. Castañeda, A. Obeso \\ Departamento de Bioquímica y Biología Molecular y Fisiología e, Instituto de Biología y Genética Molecular, Facultad de Medicina, \\ Universidad de Valladolid y Consejo Superior de Investigaciones Científicas, 47005 Valladolid, Spain
}

Accepted 23 January 2007

\begin{abstract}
Superoxide anion is the most important reactive oxygen species (ROS) primarily generated in cells. The main cellular constituents with capabilities to generate superoxide anion are NADPH oxidases and mitochondrial respiratory chain. The emphasis of our article is centered in critically examining hypotheses proposing that ROS generated by NADPH oxidase and mitochondria are key elements in $\mathrm{O}_{2}$-sensing and hypoxic responses generation in carotid body chemoreceptor cells. Available data indicate that chemoreceptor cells express a specific isoform of NADPH oxidase that is activated by hypoxia; generated ROS acting as negative modulators of the carotid body (CB) hypoxic responses. Literature is also consistent in supporting that poisoned respiratory chain can produce high amounts of ROS, making mitochondrial ROS potential triggers-modulators of the CB activation elicited by mitochondrial venoms. However, most data favour the notion that levels of hypoxia, capable of strongly activating chemoreceptor cells, would not increase the rate of ROS production in mitochondria, making mitochondrial ROS unlikely triggers of hypoxic responses in the CB. Finally, we review recent literature on heme oxygenases from two perspectives, as potential $\mathrm{O}_{2}$-sensors in chemoreceptor cells and as generators of bilirubin which is considered to be a ROS scavenger of major quantitative importance in mammalian cells.
\end{abstract}

(C) 2007 Elsevier B.V. All rights reserved.

Keywords: $\mathrm{O}_{2}$-sensing; Carotid body; Reactive oxygen species; NADPH oxidase; Respiratory chain; Heme oxygenase

\section{Introduction}

In recent review articles from our laboratory we have examined the possible significance of reactive oxygen species in oxygen-sensing, with a particular focus in oxygen-sensing in the carotid body (CB) chemoreceptor cells and with some references to oxygen sensing in pulmonary artery smooth muscle cells. In the first article (Gonzalez et al., 2002), following classical studies on neurotransmitters and second messengers we enunciated several criteria that ROS should met to be considered true specific-signaling molecules or second messengers. Our conclusion at that time was none of the required criteria were unequivocally satisfied. In a second article (Gonzalez et al., 2003) a special emphasis was given to the mechanisms or reactions proposed to be involved in ROS signaling, and we reviewed what was known about those reactions in the CB chemoreceptors. Once again we concluded that available literature did not allow ascribe

\footnotetext{
* Corresponding author at: Departamento de Bioquímica y Biología Molecular y Fisiología, Facultad de Medicina, Universidad de Valladolid, 47005 Valladolid, Spain. Tel.: +34 9834230 89; fax: +34 983423588 .

E-mail address: constanc@ibgm.uva.es (C. Gonzalez).
}

ROS a specific signaling role. In the third article (Gonzalez et al., 2004) we reviewed the potential pitfalls that optical methods used to assess ROS levels/rate of production have, and the potential advantages of using alternative, i.e., fingerprinting methods to assess the redox environment of the cells. Particular attention was given to the reliability of the measurement of reduced and oxidized glutathione (GSH and GSSG, respectively) levels and the calculation of the redox status to assess the rate of ROS production in cells; however, the sensitivity of this method is low in comparison to optical methods. Another aspect that we dealt with in this last article was the concept of hypoxia itself and the range of $P_{\mathrm{O}_{2}}$ at which chemoreceptor cells (and pulmonary artery smooth muscle cells) become activated by hypoxia, emphasizing that their threshold of activation is an arterial (or alveolar) $P_{\mathrm{O}_{2}}$ of $70-75 \mathrm{mmHg}$ and their maximal response takes place at arterial $P_{\mathrm{O}_{2}}$ in the range of $10-15 \mathrm{mmHg}$; these ranges of $P_{\mathrm{O}_{2}}$ are certainly well above those normally used in most in vitro preparations employing cell cultures and stable lines.

The present article is focused on the genesis of ROS and the reactivity of these complex group of molecules. The goal that we intend to achieve is to provide the reader with a clear picture of the potential drawbacks of using redox-active drugs. 
Interspersed with those notions we make continuous references and comments to specific findings obtained in the $\mathrm{CB}$ and in pulmonary artery smooth muscle cells. Based on those findings, ideally the conclusion of our article would be an unambiguous answer, i.e., ROS play or do not play a role in oxygen sensing. However, facts seem to drive us to answer that ROS may play an ill-defined role.

\section{General concepts on free radicals and ROS}

A free radical is any molecular species capable of independent existence containing one or more unpaired electrons. In biology, most attention is paid to oxygen radicals, but in fact there is a wide spectrum of molecular species in living cells having unpaired electrons. ROS is a wider term that includes oxygen free radicals and any other oxygen-containing molecule in which an oxygen atom has a greater reactivity than molecular $\mathrm{O}_{2}$. A free radical can be formed by the gain or by the loss of a single electron by any non-radical molecule: $\mathrm{A}+\mathrm{e}^{-} \rightarrow \mathrm{A}^{\bullet-} ; \mathrm{A} \rightarrow \mathrm{A}^{\bullet+}+\mathrm{e}^{-}$. The most familiar molecule being converted to free radical by gaining one electron in biological systems is the superoxide anion $\left(\mathrm{O}_{2}+\mathrm{e}^{-} \rightarrow \mathrm{O}_{2}{ }^{\bullet-}\right) . \mathrm{O}_{2}{ }^{\bullet-}$ and $\mathrm{H}_{2} \mathrm{O}_{2}$ (hydrogen peroxide) represent the most important primary ROS generated by cells, most other ROS resulting from secondary reactions of these two primary ROS. $\mathrm{O}_{2}^{\bullet-}$ can be protonized to form $\mathrm{HO}_{2}{ }^{\bullet}$ (hydroperoxyl radical) which is a stronger reducing agent and, in addition, is freely permeable to membranes (it has no charge). These two properties make $\mathrm{HO}_{2}{ }^{\bullet}$ an important free radical even though its concentration in biological systems is $1 / 100-400$ that of $\mathrm{O}_{2}{ }^{\bullet-}$. Hydroperoxyl radical is involved in the spontaneous dismutation of $\mathrm{O}_{2}{ }^{\bullet-}$ $\left(\mathrm{HO}_{2}^{\bullet}+\mathrm{O}_{2}^{\bullet-}+\mathrm{H}^{+} \rightarrow \mathrm{H}_{2} \mathrm{O}_{2}+\mathrm{O}_{2}\right)$.

When in any given molecule a covalent bond is broken and one electron from the pair of electrons shared remains in each of the resulting molecules (or atoms), a process known as homolytic fission, both resulting species are free radicals. Homolytic fission is a process requiring high energy which is commonly provided by high energy radiations (X-rays and $\gamma$ radiations). For example, the cleavage of one of the $\mathrm{O}-\mathrm{H}$ bonds in water molecule by high-energy radiations (water radiolysis) might constitute an important source of free radicals:

\section{$\mathrm{H}_{2} \mathrm{O} \rightarrow \mathrm{H}^{\bullet}$ (hydrogen radical) $+\mathrm{OH}^{\bullet}$ (hydroxyl radical)}

Utraviolet light, and higher wavelength visible lights, do not have sufficient energy to produce radiolysis of water, but in the presence of some sensitizer molecules, can generate homolytic scission of $\mathrm{H}_{2} \mathrm{O}_{2}$ in the skin $\left(\mathrm{H}_{2} \mathrm{O}_{2} \rightarrow 2 \mathrm{OH}^{\bullet}\right)$. At high altitude where the UV-radiation intensity is higher than at sea level this source of hydroxyl radical might be quantitatively very important and account for the higher rate of incidence of precancerous and cancerous skin lesions in high altitude inhabitants and mountain centered sport practitioners (Pattison and Davies, 2006). Violet-blue light, which is used as excitation light for some fluorescent indicators used to monitor the rate of ROS production can produce photoreduction of flavins and activation of flavincontaining oxidases (Hockberger et al., 1999). Activation of oxidases generates $\mathrm{H}_{2} \mathrm{O}_{2}$ which in the presence of free transi- tion metals can generate $\mathrm{OH}^{\bullet}$ by the Fenton reaction (see below; Hockberger et al., 1999). The low specificity of most fluorescent indicators towards different ROS species (Ischiropoulos et al., 1999) and the increased probability for occurrence of these potential reactions with the intensity and duration of the excitation light pulses, should be carefully considered when using optical methods to assess the rate of ROS production.

In previous articles from our laboratory (Gonzalez et al., 2003, 2004) we have discussed the problems associated with the use of fluorescent ROS indicators and argued that dihydroethidium is considered to a reliable indicator to assess the rate of $\mathrm{O}_{2}{ }^{\bullet-}$ production (Benov et al., 1998). Nonetheless, there are some observations in our previous experiments (He et al., 2005) and in those of Kevin et al. (2003) that do not fit the reliability concept, i.e., that dihydroethidium, upon its reaction with ROS (mostly $\mathrm{O}_{2}{ }^{\bullet-}$ ), generates fluorescent oxidized products which remain trapped inside the cells and therefore quantification of the fluorescence yields a measurement of the amount of ROS produced. In both of these studies it has been found that short pulses of sodium azide or full ischemia generated fluorescent signals that disappear on the elimination of the sodium azide or on restitution of the flow. In neither article is provided a tentative explanation for the observation. Since in both studies cytochrome $c$ would become fully reduced, we speculate that the oxidized fluorescent products formed by ROS generated upstream in the respiratory chain would be back reduced by ferrocytochrome $c$; alternatively, it is also conceivable that burst-like oxidation of cytochrome $c$ to ferricytochrome $c$ upon removal of sodium azide or on termination of the ischemia generates concentrations of oxidized cytochrome $c$ which forces further oxidation of the fluorescent products generating molecular species with emissions beyond the recording window (Benov et al., 1998). Our proposal is based on the fact that, to our knowledge, it has never been observed a disappearance of the fluorescent signals from the dihydroethidine oxidized products resulting from inhibition of the proximal mitochondrial complexes, and from the fact that cytochrome $c$ is well known to interact in different manners with fluorescent indicators (e.g., Benov et al., 1998; Ohashi et al., 2002).

Although the most important ROS are $\mathrm{H}_{2} \mathrm{O}_{2}$ (hydrogen peroxide), $\mathrm{O}_{2}^{\bullet-}$ (superoxide radical), $\mathrm{OH}^{\bullet}$ (hydroxyl radical) and hypochlorous acid $(\mathrm{HOCl})$, there are other ROS which are free radicals such as hydroperoxyl radical $\left(\mathrm{HO}_{2}{ }^{\bullet}\right)$, alkoxyl radicals $\left(\mathrm{RO}^{\bullet}\right)$ and peroxyl radicals $\left(\mathrm{RO}_{2}{ }^{\bullet}\right.$; in fact $\mathrm{HO}_{2}{ }^{\bullet}$ is the simplest peroxyl radical), and other free radicals in which the reactive atom is not oxygen. Among this last group the biologically most relevant radicals include: (1) transition metals such as iron, copper and manganese which have several unpaired electrons and have two main oxidation numbers $\left(\mathrm{Fe}^{2+}\right.$ and $\mathrm{Fe}^{3+} ; \mathrm{Cu}^{+}$and $\mathrm{Cu}^{2+} ; \mathrm{Mn}^{2+}$ and $\mathrm{Mn}^{3+}$ ) allowing them to accept or to donate one electron; (2) carbon-centered-radicals formed by abstraction of an atom of hydrogen from a $\mathrm{C}-\mathrm{H}$ bond $\left(\mathrm{R} \equiv \mathrm{C}-\mathrm{H}+\mathrm{OH}^{\bullet} \rightarrow \mathrm{R} \equiv \mathrm{C}^{\bullet}+\mathrm{H}_{2} \mathrm{O}\right)$; (3) sulphur-centered radicals (thiyl radicals) formed upon reaction of $\mathrm{SH}$-containing molecules with transition metals (reduced glutation, $\mathrm{GSH}+\mathrm{Fe}^{3+} \rightarrow \mathrm{GS}^{\bullet}+\mathrm{Fe}^{2+}+\mathrm{H}^{+}$) or by homolytic fission of disulfide bonds in proteins or oxidized 
glutathione (GS-SG $\rightarrow \mathrm{GS}^{\bullet}+\mathrm{GS}^{\bullet}$ ); (4) another biologically very important group of reactive species are reactive nitrogen species (RNS) with an ample group of molecular entities some of them being free radicals (nitric oxide, $\mathrm{NO}^{\bullet}$ and nitrogen dioxide $\mathrm{NO}_{2}^{\bullet}$ ) and other being non-radicals, with peroxynitrite anion $\left(\mathrm{ONOO}^{-}\right)$; peroxynitrous acid $(\mathrm{ONOOH})$ and alkylperoxynitrites (ROONO).

We are going to focus our article on ROS; however, being $\mathrm{O}_{2}{ }^{\bullet-}$ the most important primary ROS, superoxide anion would constitute the frame of our article. Nonetheless, in presenting the mechanisms involved $\mathrm{O}_{2}{ }^{\bullet-}$ generation and the general aspects of its reactivity, we will also be referring to most of the reactive molecules mentioned above. A short final section would be devoted to heme oxygenases and the biliverdin-bilirubin cycle.

\section{Superoxide anion}

\subsection{Origin}

In preceding paragraphs we have stated that the quantitatively most important primary free radical produced by gaining one electron in biological systems is superoxide anion $\left(\mathrm{O}_{2}+\mathrm{e}^{-} \rightarrow \mathrm{O}_{2}{ }^{\bullet-}\right)$. Therefore, we examine first where in biological systems molecular oxygen can gain one electron.

\subsubsection{Erythrocytes}

Following the path of $\mathrm{O}_{2}$ in the organism we shall start by considering the formation of $\mathrm{O}_{2}{ }^{\bullet-}$ during its transport in blood. In aerated ferrous salt solutions, the $\mathrm{Fe}^{2+}$ ion can be slowly oxidized to $\mathrm{Fe}^{3+}$ by cession of one electron to $\mathrm{O}_{2}$ : $\mathrm{Fe}^{2+}+\mathrm{O}_{2} \leftrightarrow \leftrightarrow \leftrightarrow \mathrm{Fe}^{3+}+\mathrm{O}_{2}^{\bullet-}$, the ferric ion being most stable. However the ability of $\mathrm{Fe}^{2+}$ to be oxidized is greatly affected by ligands, acquiring a low-spin configuration with higher difficulty to be oxidized to $\mathrm{Fe}^{3+}$. This is the configuration of $\mathrm{Fe}^{2+}$ in hemoglobin, and thereby its slow rate of oxidation. However, there is a certain degree of delocalization of one of the electrons in the heme- $\mathrm{Fe}^{2+}$ when $\mathrm{O}_{2}$ is bound appearing a resonant "equilibrium":

heme- $\mathrm{Fe}^{2+}-\mathrm{O}_{2} \leftrightarrow$ heme- $\mathrm{Fe}^{3+}-\mathrm{O}_{2}^{\bullet-}$

Upon dissociation of oxyhemoglobin, the heme- $\mathrm{Fe}^{2+}$ normally keeps the delocalized electron, but occasionally (3\% of hemoglobin/day) the electron is kept by $\mathrm{O}_{2}$ and then hemoglobin releases $\mathrm{O}_{2}{ }^{\bullet-}$, the $\mathrm{Fe}^{2+}$ is transformed into $\mathrm{Fe}^{3+}$ and hemoglobin is transformed into methemoglobin, unsuitable to bind $\mathrm{O}_{2}$. Erythrocytes possess an enzymatic system (methemoglobin reductase) to reduce methemoglobin to hemoglobin to recover their $\mathrm{O}_{2}$-transporting function, and important enzymatic mechanisms to dispose $\mathrm{O}_{2}{ }^{\bullet-}$, including copper-zinc superoxide dismutase (SOD) to transform the $\mathrm{O}_{2}{ }^{\bullet-}$ in to $\mathrm{H}_{2} \mathrm{O}_{2}$ and high levels of glutathione peroxidase (GPx; along with high levels of reduced glutathione, $\mathrm{GSH}$ ), which transforms $\mathrm{H}_{2} \mathrm{O}_{2}$ into water $\left(2 \mathrm{GSH}+\mathrm{H}_{2} \mathrm{O}_{2} \rightarrow \mathrm{GSSG}+2 \mathrm{H}_{2} \mathrm{O}\right)$ and, catalase which transforms $\mathrm{H}_{2} \mathrm{O}_{2}$ into water plus $\mathrm{O}_{2}\left(2 \mathrm{H}_{2} \mathrm{O}_{2} \rightarrow 2 \mathrm{H}_{2} \mathrm{O}+\mathrm{O}_{2}\right)$. The oxidized glutathione (GSSG) is reconverted in $2 \mathrm{GSH}$ by glutathione reductase which uses NADPH as donor of reducing equivalents; NADPH is generated in the powerful pentose phosphate pathway present in erythrocytes. Increased rate of $\mathrm{H}_{2} \mathrm{O}_{2}$ production implies consumption of $\mathrm{GSH}$ and generation of GSSG and a decrease in the redox environment of the cells $\left(\mathrm{E}_{\mathrm{GSH}}=E_{\mathrm{GSH}}^{\circ}-R T / z F \times \ln [\mathrm{GHS}]^{2} /[\mathrm{GSSG}]\right.$; Schafer and Buettner, 2001). If the production of $\mathrm{H}_{2} \mathrm{O}_{2}$ is very intense, cells export GSSG to the extracellular milieu in an attempt to maintain the intracellular environment of the cells as much reduced as possible, with the obvious consequence of great diminution of the total levels of glutathione (Sharma et al., 2000; Schafer and Buettner, 2001). This full set of coupled enzymatic reactions (Fig. 1) are the main responsible for ROS elimination in

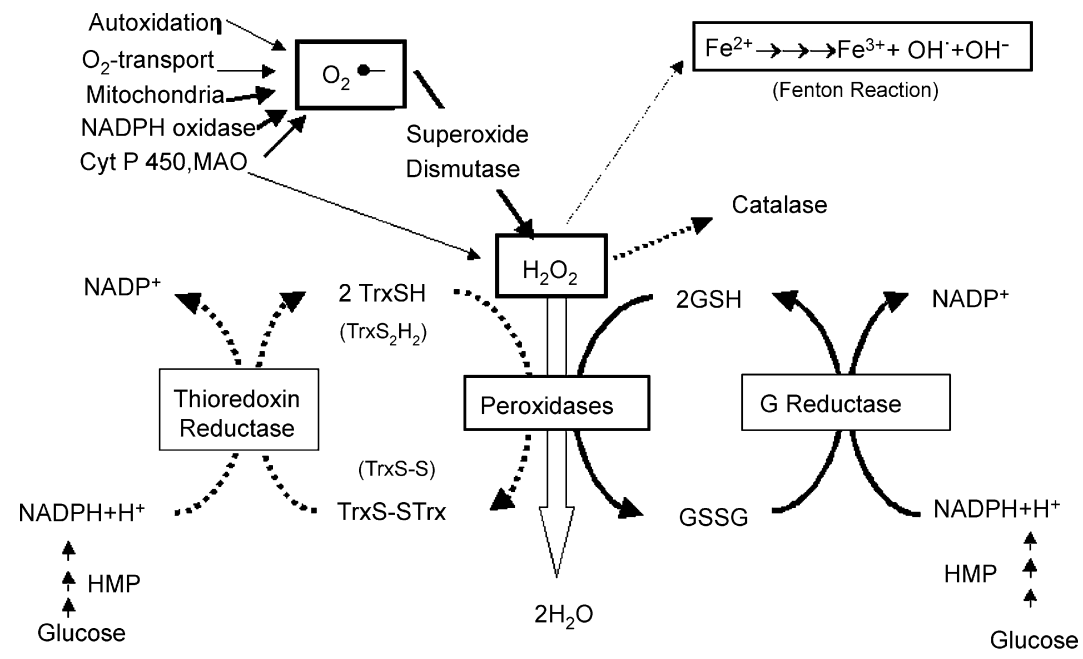

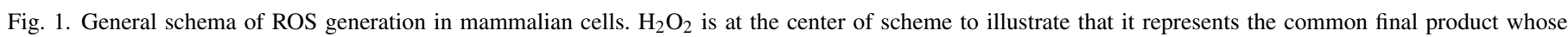

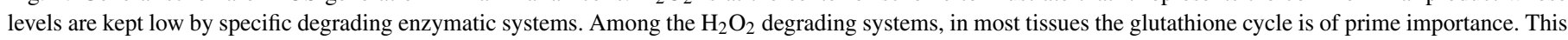

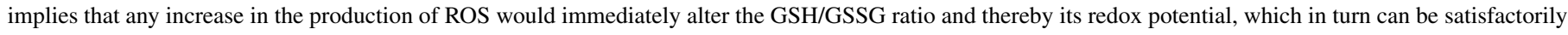

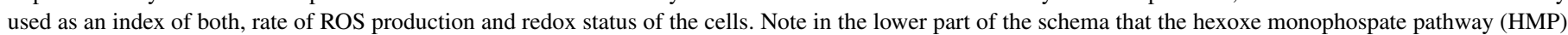

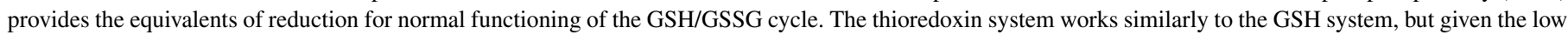
concentration of thioredoxin its role in determining the overall redox status of the cells is minor. 


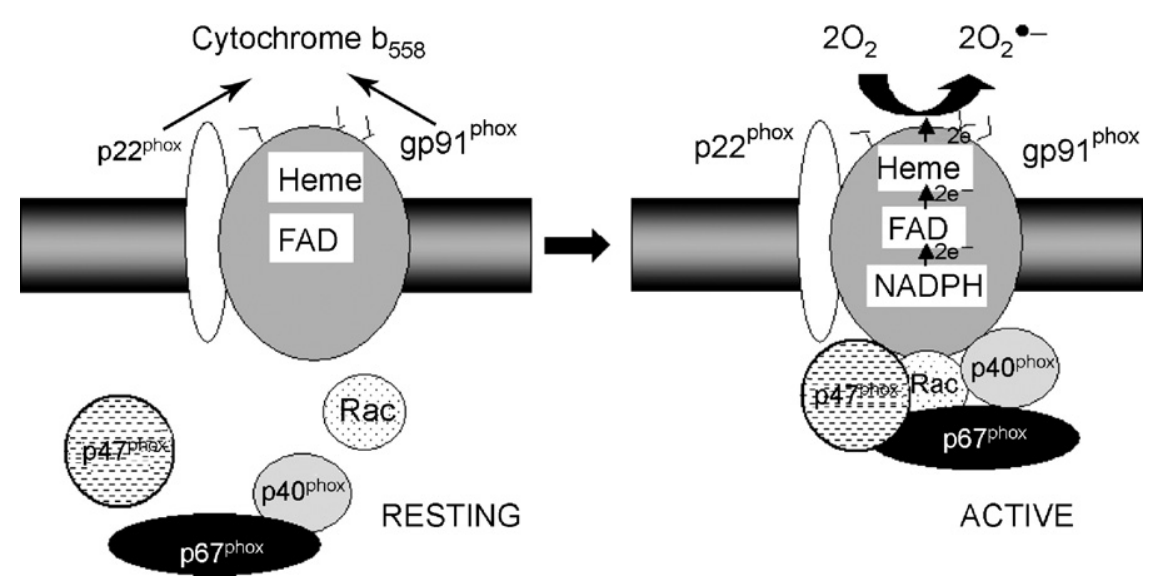

Fig. 2. Schema showing the molecular components of NADPH oxidase and their assembly to achieve enzymatic activity. Being p47phox shared by most of NADPH oxidase isoforms and a key element in promoting the functional assembly of all subunits, its genetic elimination will render the enzymes inactive.

all mammalian cells. In all mammalian cells, including erythrocytes, transition metals in their reduced form, as exemplified by $\mathrm{Fe}^{2+}$ can react with $\mathrm{H}_{2} \mathrm{O}_{2}$ in the Fenton reaction (operationally defined as the ability of $\mathrm{H}_{2} \mathrm{O}_{2}$ to oxidize many organic molecules in the presence of transition metals):

$\left(\mathrm{Fe}^{2+}+\mathrm{H}_{2} \mathrm{O}_{2} \rightarrow \rightarrow \rightarrow \mathrm{Fe}^{3+}+\mathrm{OH}^{\bullet}+\mathrm{OH}^{-}\right)$

$\mathrm{OH}^{\bullet}$ has a very high oxidizing power (reduction potential $=+1900 \mathrm{mV}$ ) being capable of initiating destructive chain reactions (e.g., membrane lipid peroxidation and fatty acids rupture) until some scavenger molecule (a molecule capable of reacting with a free radical without being itself transformed into a new radical) is able of reacting with the radicals and stop the reaction. Although $\mathrm{H}_{2} \mathrm{O}_{2}$ rate of production is relatively high in all cells representing around $1-3 \%$ of the total $\mathrm{O}_{2}$ consumption (mostly as a secondary ROS due to dismutation of $\mathrm{O}_{2}{ }^{\bullet-}$; Halliwell and Gutteridge, 1999), Fenton reaction in healthy cells is kept to a minimum because the $\mathrm{H}_{2} \mathrm{O}_{2}$ disposing systems (catalase and GPx) keep its concentration very low (in the low nanomolar range; Chance et al., 1979) and because the concentrations of transition metals as free ions is even lower. Transition metals form complexes, usually with proteins, to limit their reactivity.

We have brought the production of ROS by erythrocytes by two reasons: first, because the ROS disposal mechanisms just described in erythrocytes are common for all mammalian cells, albeit with different relative importance from cell to cell, and therefore its description at the outset of the article enlightens the situation in any other cell system; and secondly, because it is well known that auto-oxidation of hemoglobin is favored in situations of hypoxia when it is only partially oxygenated (Rifkind et al., 1991; Ciccoli et al., 2004), a circumstance seldom considered in in vivo experiments when animals are exposed to hypoxia. In fact, preliminary experiments from our laboratory would suggest that blood-generated ROS in chronic hypoxia can create a general prooxidant status in all tissues potentially capable of altering oxygen transduction cascades (GonzalezMartín et al., 2007).

\subsubsection{NAPDH oxidase}

A second place for ROS generation are phagocytic cells. Phagocyte cells, neutrophils and monocytes, as well as tissue macrophages, possess a strong enzymatic system to generate $\mathrm{O}_{2}{ }^{\bullet-}$. We are referring to NADPH oxidase, which catalyzes one electron reduction of $\mathrm{O}_{2}$ to form $\mathrm{O}_{2}{ }^{\bullet-}$ using $\mathrm{NADPH}$ as electron donor according to the overall reaction: $\mathrm{NADPH}+2 \mathrm{O}_{2} \rightarrow \mathrm{NADP}^{+}+\mathrm{H}^{+}+2 \mathrm{O}_{2}{ }^{\bullet-}$ (Fig. 2). $\mathrm{NADPH}$ oxidase (see Dinger et al., 2007) is an enzymatic complex composed of a number cytosolic subunits, p67phox, p47phox, p40phox, and Rac1/Rac2, and two membrane subunits which conform cytochrome $b_{558}$, gp91phox and p22phox. In resting phagocytes the enzyme complex is inactive, but extracellular stimuli (typically foreign particles including bacteria and fungi) through membrane receptor-mediated interactions promote phosphorylation of p47phox which plays a critical role in the overall assembly of all subunits to generate the active complex and the production of $\mathrm{O}_{2}{ }^{\bullet-}$. Superoxide is released into the phagocytic vesicles where it would exert its killing activity. There are several mechanisms which, in conjunction, transform the mild reactive $\mathrm{O}_{2}{ }^{\bullet-}$ into more destructive radicals. First, superoxide can be protonized, to the more reactive and freely permeable $\mathrm{HO}_{2} \bullet$ radical; second, it can also be spontaneously dismutated to $\mathrm{H}_{2} \mathrm{O}_{2}$, also permeable into bacteria, which in turn can generate $\mathrm{OH}^{\bullet}$ via Fenton reaction; third, it can react with hypochlorus acid (a strong oxidant per se) simultaneously produced by the myeloperoxidase of phagocytes to generate $\mathrm{OH}^{\bullet}\left(\mathrm{HOCl}+\mathrm{O}_{2}{ }^{\bullet-} \rightarrow \mathrm{O}_{2}+\mathrm{Cl}^{-}+\mathrm{OH}^{\bullet}\right)$; and fifth, in addition, $\mathrm{HOCl}$ can react with transition metals oxidizing them and generating $\mathrm{OH}^{\bullet}\left(\mathrm{HOCl}+\mathrm{Fe}^{2+} \rightarrow \mathrm{Fe}^{3+}+\mathrm{Cl}^{-}+\mathrm{OH}^{\bullet}\right)$ or can decompose spontaneously to form $\mathrm{Cl}_{2}$ gas that is also very toxic $\left(\mathrm{HOCl}+\mathrm{H}^{+} \rightarrow \mathrm{Cl}_{2}+\mathrm{H}_{2} \mathrm{O}\right)$. Thus, phagocyte NADPH oxidase, and by that mater phagocyte $\mathrm{O}_{2}{ }^{\bullet-}$, plays a crucial defensive role in natural innate defense against microorganisms.

There was early evidence in the literature suggesting the presence of NAPDH oxidase activity in several cell types (Cross and Jones, 1991), but it was at the outset of this millennium that was shown that several NADPH oxidase isoforms do in fact exist. Today, the family of NADPH oxidases is known as the Nox family and has seven members: including Nox1, Nox2 
Table 1

Tissue distribution and function of Nox members

\begin{tabular}{|c|c|c|}
\hline Enzyme & Site of expression & Function \\
\hline Nox 1 & Colon, stomach, vascular smooth muscle, prostate, uterus & Blood pressure regulation; host defense \\
\hline Nox 2 & Myeloid cells & Host defense; signaling? \\
\hline Nox3 & Inner ear, fetal tissues & Otoconia biosynthesis \\
\hline Nox4 & Kidney, endothelium, carotid body chemoreceptor cells & Oxygen sensing; vasoregulation?; Signaling? \\
\hline Nox 5 & Lymph nodes, spleen, testis & Signaling?; Capacitation? \\
\hline Duox 1 and Duox 2 & Thyroid, lung, salivary glands, gastrointestinal tract & Hormone synthesis; host defense? Signaling? \\
\hline
\end{tabular}

(formerly known as gp91 ${ }^{\text {phox }}$, the phagocyte isoform), Nox3, Nox4, Nox5, Duox 1 and Duox2. Table 1, modified from Geiszt (2006), provides the location and function of all these members.

Aside from eliminating some aspects contained in the original table (alternative names and regulation mechanisms), two modifications have been included in the table that are of interest for the present article. First, based in preliminary evidence (He et al., 2004, also unpublished), we have included CB chemoreceptor cells as a specific place of expression of Nox4 because we have immunocytochemically located it in chemoreceptor cells and found that its transcription rate increases in animals exposed to a $10 \%$ atmosphere for 7 days. Second, we ascribe a role to Nox4 in oxygen chemoreception because we have provided evidence that NADPH oxidase-derived (Nox4) derived ROS act as negative second messengers of the hypoxic transduction cascade in chemoreceptor cells and the overall oxygen chemoreception process (He et al., 2005; see article by Dinger et al., 2007). It should be mentioned that in addition to Nox 4 we have searched for Nox 2 in CB sections and found that it does not co-localize with the chemoreceptor cell marker tyrosine hydroxylase, its expression being restricted to the stroma of the organ. No other Nox isoforms have been searched for in the CB.

The subcellular location of several Nox members varies from isoform to isoform, and in some instances a given isoform (e.g., Nox 4) can have different locations (e.g., nucleus and endoplasmic reticulum). Some isoforms exhibit constitutive activity and are regulated by intracellular second messengers including intracellular $\mathrm{Ca}^{2+}$ (e.g., Nox5 and Duox1-2) and probably also Nox4 in chemoreceptor cells because while hypoxia activates ROS production, if the hypoxic stimulus is applied in conjunction with $\mathrm{Ca}^{2+}$ channel blockers the ROS-generated signals is drastically reduced (unpublished observation); this regulation makes conceivable that ROS generated by these enzymes could be important in cell signaling. The combination of second messenger regulation and the potentially restricted release of ROS into specific cell compartments would make ROS produced by these Nox members suitable modulators of transduction cascades. In this regard, there are two groups of recent data that deserve some comments. The first group of data was obtained by comparing responses in chemoreceptor cells from control and knockout mice for the p47phox subunit of NADPH oxidase (He et al., 2005). Mice CB chemoreceptor cell $\mathrm{K}^{+}$currents are in a large percentage sensitive to iberiotoxin, indicating that they are carried through maxi-K channels, although other $\mathrm{KV}$ channels, some of them sensitive to hypoxia, have also been described in mice cells (Perez-Garcia et al., 2004). In control (wild type) mice chemoreceptor cells, where hypoxia increases the production of ROS generated by Nox4, a specific inhibitor of NADPH oxidase augmented hypoxic inhibition of the voltagedependent $\mathrm{K}$ currents and low concentrations of $\mathrm{H}_{2} \mathrm{O}_{2}$ decreased their hypoxic inhibition. In chemoreceptor cells of $\mathrm{p} 47 \mathrm{phox}$ null mice, where hypoxia did not augment the production of ROS, the percentage hypoxic inhibition of voltage-dependent $\mathrm{K}$ currents is greater than in cells from control animals, and the NADPH oxidase inhibitor did not affect the effect of hypoxia. These findings indicate, first that $\mathrm{K}$ current inhibition occurs in chemoreceptor cells lacking a functional NADPH oxidase, i.e., this enzyme complex is not the $\mathrm{O}_{2}$-sensor (or the unique $\mathrm{O}_{2}$-sensor), and second, that NADPH oxidase-derived ROS lessen the effects of hypoxia on voltage-dependent $\mathrm{K}^{+}$currents, i.e., ROS would behave as negative second messengers of the hypoxic response (see below, under Section 3.1.3). The second group of data has been obtained in TASK-1 transfection experiments in HEK cells that expressed Nox4 endogeneously (Lee et al., 2006). The observations were that TASK-1 and Nox4 colocalize in the plasma membrane, that hypoxia inhibited TASK-1 currents and that elimination of endogenous Nox4 expression with siRNA techniques abolished the sensitivity to hypoxia; in addition, overexpression of Nox-4 in HEK cells by simultaneous cotransfection of TASK-1 and Nox4 augmented the hypoxic inhibition of the TASK-1 current. If the same association between TASK channels and Nox 4 occurs in chemoreceptor cells, then it can be postulated that ROS locally released in the vicinity of the plasma membrane would play a double role: in the one hand, they would provide TASK channels with a mechanism to trigger their inhibition by hypoxia and chemoreceptor cell depolarization, as this has been the functional role given to TASK channels in chemoreceptor cells (see Buckler et al., 2006), and in the other hand they would tend to modulate negatively the hypoxic transduction cascade by lessening the effects of hypoxia on hypoxic sensitive $\mathrm{Kv}$ channels. However, the just commented findings in p47phox null chemoreceptor cells would not favor the first of the two proposed roles. It is conceivable the existence of more than one mechanism coupling hypoxia to TASK channels (see Buckler et al., 2006) capable of independently generating maximal hypoxic inhibition of TASK channels.

Yet inspection of Table 1 permits to assert that known functions of Nox members and of their products are few. In another recent article Leto and Geiszt (2006) put forward the notion that probably several Nox members play an ancestral role in antimicrobial defense present in most cells, being in this regard 


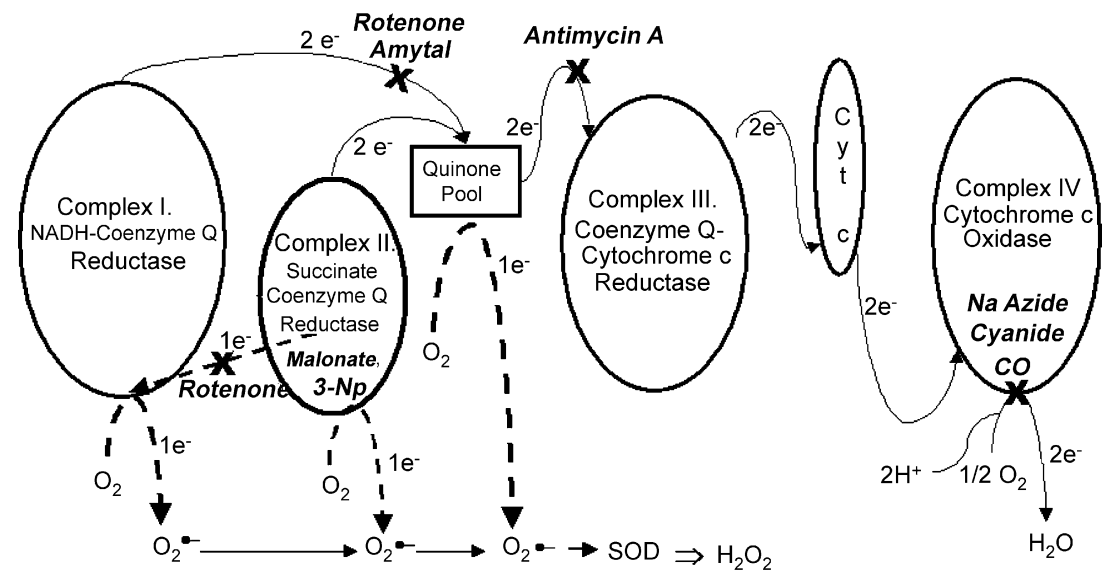

Fig. 3. Schema of the mitochondrial respiratory chain illustrating the complexes where $\mathrm{O}_{2}{ }^{\bullet-}$ can be generated. The schema also shows the most commonly used inhibitors of the respiratory chain to evidence that the inhibitors acting downstream of the complexes where production of $\mathrm{O}_{2}{ }^{\bullet-}$ occurs, would increase while those acting upstream will inhibit $\mathrm{O}_{2}{ }^{\bullet-}$ production. Note that from complex II electrons can flow backwards to complex I; this backflow of electrons, which is rotenone sensitive, can be a major source of $\mathrm{O}_{2}{ }^{\bullet-}$ in situations where substrates to complex I are limited, as it might occur in diabetes and starvation 3Np (3-nitropropionic acid).

a diffuse innate defense mechanism expressed in all phyla of the animal kingdom and even in plants.

\subsubsection{Mitochondria}

In any cell type, mitochondria represent a potential source for ROS generation, however the output of ROS from this source is highly debated. First, it should be stated that the primary ROS produced by mitochondria is $\mathrm{O}_{2}{ }^{\bullet-}$, although secondarily it can be promote the genesis of basically any ROS and RNS (see below under Section 3.2).

A special consideration should be given to monoamine oxidases (MAO). The FAD-containing oxidases catalyze two different types of reactions (Toninello et al., 2004):

(a) Elimination of the primary amino group from biogenic amines (e.g., dopamine)

$$
\begin{aligned}
& E_{\mathrm{ox}}+\mathrm{R}-\mathrm{CH}_{2}-\mathrm{NH}_{3}{ }^{+} \rightarrow E_{\mathrm{red}}-\mathrm{NH}_{3}{ }^{+}+\mathrm{RCHO} \\
& E_{\mathrm{red}}-\mathrm{NH}_{3}{ }^{+}+\mathrm{O}_{2} \rightarrow E_{\mathrm{ox}}+\mathrm{NH}_{4}^{+}+\mathrm{H}_{2} \mathrm{O}_{2}
\end{aligned}
$$

(b) Cleavage of the $\mathrm{C}-\mathrm{N}$ bond in secondary amino groups:

$$
\begin{aligned}
& \mathrm{R}_{1}-\mathrm{CH}_{2}-\mathrm{NH}-\mathrm{CH}_{2}-\mathrm{R}_{2}+\mathrm{O}_{2}+\mathrm{H}_{2} \mathrm{O} \\
& \quad \rightarrow \mathrm{R}_{1}-\mathrm{CHO}+\mathrm{H}_{2} \mathrm{~N}-\mathrm{CH}_{2}-\mathrm{R}_{2}+\mathrm{H}_{2} \mathrm{O}_{2}
\end{aligned}
$$

The first reaction is catalyzed by MAOs (which pharmacologically were classified as MAO-A and MAO-B and molecularly they are indeed different isoforms) which are located in the inner part of the outer mitochondrial membrane. The second reaction is catalyzed by cytoplasmic oxidases, PAOs, and participate in the biogenesis of polyamines. We bring these reactions into this article because the $\mathrm{CB}$ has very high concentrations of biogenic amines, mostly dopamine (DA) and norepinephrine (NE), which are oxidized by MAO (Gonzalez et al., 1994) and therefore can generate important amounts of $\mathrm{H}_{2} \mathrm{O}_{2}$. The second reaction, usually known as the interconversion reaction of polyamines might also be important in chemoreceptor cells (Ganfornina et al., 2005; also unpublished) because the transcription rate of some of the enzymes involved in the biogenesis of polyamines is increased in the $\mathrm{CB}$ upon exposure to chronic hypoxia.

Where in mitochondria is $\mathrm{O}_{2}{ }^{\bullet-}$ generated? Or may be the question could be reformulated in this terms, where in mitochondria exist the capabilities to generate $\mathrm{O}_{2}{ }^{\bullet}$ ? Many authors would agree that complexes I and III of the respiratory chain are the main potential locus of $\mathrm{O}_{2}{ }^{\bullet-}$ generation (Turrens, 2003; Muller et al., 2004; Chen et al., 2005; Fig. 3) with some authors suggesting also that it can be generated at the level of complex II (Gredilla et al., 2001). It should be noted that the contribution of one or another complex appears to vary from tissue to tissue, with heart mitochondria producing $\mathrm{O}_{2}{ }^{\bullet-}$ mainly at complex III and brain mitochondria at the level of complex I, being in this last case due to backflow of electrons from complex II (Votyakova and Reynolds, 2001; Turrens, 2003). In this regard, the findings of Votyakova and Reynolds (2001) are very illustrative: in brain mitochondria fueled with complex I substrates the productionrelease of $\mathrm{H}_{2} \mathrm{O}_{2}$ to the incubating solution was undetectable, but it was very intense (and rotenone sensitive) if mitochondria are fueled with succinate. Thus, it would appear that in situations of forced production of succinyl-CoA as it happens in situations of unavailability of glucose (e.g., diabetes and starving) and forced oxidation of branched-chain aminoacids the production of ROS by the mitochondria may be exaggerated.

Another important point to consider is that the capability of mitochondria to produce ROS has been established mainly on isolated mitochondria and also in isolated mitochondria particles with the standard experimental paradigm of inhibiting one or another component of the respiratory chain and the assessment of the ROS production with several methods. Leaving aside considerations on the preparations (isolated mitochondria or the less physiological preparations of isolated particles; see below) and on the methods of ROS measurement (see Gonzalez et al., 2004; see also above), it should be underlined as a fixed rule that 
when a component (complex) of the respiratory chain is inhibited, all the components of the respiratory chain proximal to the point of inhibition become reduced, with the distal components becoming oxidized, as they would "empty" their electrons into molecular $\mathrm{O}_{2}$ to form $\mathrm{H}_{2} \mathrm{O}$. The obvious consequence is that after inhibition of the respiratory chain at a given point, ROS production takes place at the complexes that are proximal to the point of inhibition, because they are the reduced components and therefore they are capable of giving up electrons to $\mathrm{O}_{2}$ to form $\mathrm{O}_{2} \bullet-$. This in turn implies that the rate of feeding of the complexes proximal to the inhibition point with equivalents of reduction would determine the rate of $\mathrm{O}_{2}{ }^{\bullet-}$ production in a given period of time (Kussmaul and Hirst, 2006). In addition, as stated by Turrens (2003) the rate of $\mathrm{O}_{2}{ }^{\bullet-}$ production would depend on the availability of $\mathrm{O}_{2}$ to accept the single electrons:

$\frac{\mathrm{d}\left[\mathrm{O}_{2}^{\cdot-}\right]}{\mathrm{d} t}=k\left[\mathrm{O}_{2}\right]\left[\mathrm{RCH}_{2}\right]$

For example, the rate of production of $\mathrm{O}_{2}{ }^{\bullet-}$ at the level of complex I after the inhibition of the transference of electrons from complex I to complex III with rotenone would depend on the $P_{\mathrm{O}_{2}}$ in the matrix of the mitochondria and on the NADH/NAD ${ }^{+}$ratio (i.e., on the rate of oxidation of piruvate and malate in the Krebs cycle). Thus, in hypoxia or glucose starving cells it should be expected a decrease in the production of ROS, and the contrary would occur in hyperoxia with glucose available to oxidation. Turrens (2003) quotes work of himself performed in heart isolated mitochondria in which he observed that in hyperoxia the rate of ROS production is biphasic: with up to $60 \% \mathrm{O}_{2}$ the rate of ROS production increases slowly and above this $\mathrm{O}_{2}$ level the production increases at a faster rate, indicating probably that the mitochondrial scavenger mechanisms can cope with increased ROS production up to a certain level above which all produced ROS are not eliminated.

In considering the increased rate of production of ROS seen in hypoxia by Schumacker group (e.g., Duranteau et al., 1998 working with cardiomyocytes; see Waypa and Schumacker, 2006), Turrens (2003) envisions two factors that might contribute to the paradoxical increase in hypoxia: a decrease in the synthesis of $\mathrm{NO}^{\bullet}$ (at atmospheres of $1.5 \% \mathrm{O}_{2}$ it would decrease to $5-10 \%$ of normal rate at $20 \% \mathrm{O}_{2}$ ) that would lessen the rate of the reaction of $\mathrm{O}_{2}{ }^{\bullet-}$ with $\mathrm{NO}^{\bullet}$ (see below under Section 3.2) and therefore, more $\mathrm{O}_{2}{ }^{\bullet-}$ would be "visible" and detected with ROS indicators, and, secondly, $\mathrm{NO}^{\bullet}$ even if low in concentration might suffice (at the lower $P_{\mathrm{O}_{2}}$ ) to inhibit cytochrome oxidase by increasing its $K_{\mathrm{m}}$ for $\mathrm{O}_{2}$, and therefore all complexes of the respiratory chain would become reduced and capable of releasing electrons. Since the respiratory chain is designed to use $\mathrm{O}_{2}$ and to maintain a normal flow of electrons to molecular $\mathrm{O}_{2}$, minimizing the production of ROS, even at extreme levels of hypoxia (Gnaiger et al., 2000), the increased rate of ROS production observed in Schumacker laboratory during hypoxia might have an extramitochondrial origin.

The intimate mechanisms and the identity of the molecular component(s) allowing the leakage of one electron into molecular $\mathrm{O}_{2}$ to generate $\mathrm{O}_{2}{ }^{\bullet-}$ is complex, not always well understood, and thereby controversial. For example, in complex I it has been proposed that flavin mononucleotides (Chen et al., 2005; Kussmaul and Hirst, 2006), iron-sulfur clusters (Barja, 1999; Muller et al., 2004) and protein-associated ubisemiquinones (Ohnishi et al., 2005) are the precise places of the transference of one electron to molecular $\mathrm{O}_{2}$ to form $\mathrm{O}_{2}{ }^{\bullet-}$. Whatever the electron donor, it appears that the $\mathrm{O}_{2}{ }^{\bullet-}$ is released into the mitochondrial matrix and yet, even after treatment with rotenone which has been shown by many authors that increases markedly the production of $\mathrm{O}_{2}{ }^{\bullet-}$ when measured as $\mathrm{H}_{2} \mathrm{O}_{2}$ released from mitochondria, $\mathrm{O}_{2}{ }^{\bullet-}$ indicators known to permeate mitochondria (e.g., MCLA, a modified luciferin analog, and DHE dihydroethidine) do not generate any measurable signal. Muller et al. (2004) have suggested that the high activity of SOD and GPX in the mitochondria would compete with the indicators and prevent the genesis of the signal. Yet, in the presence of rotenone, mitochondrial aconitase activity is markedly decreased indicating that $\mathrm{O}_{2}{ }^{\bullet-}$ generated by complex I can damage some mitochondrial components (see below, under Section 3.2). With substrates generating NADH in the Krebs cycle (e.g., pyruvate) and therefore entering the respiratory chain at the level of complex I, rotenone as mentioned before increases the mitochondrial rate of $\mathrm{H}_{2} \mathrm{O}_{2}$ release to the incubating solution, but if mitochondria are incubated with succinate and therefore the reducing equivalents generated enter the respiratory chain at the complex II level, rotenone decreases the release of $\mathrm{H}_{2} \mathrm{O}_{2}$ release from mitochondria, implying that the succinate-supported ROS production (either at level of reduced FAD or succinate dehydrogenase) is in its greatest part due to backflow of electrons to complex I that is inhibited by rotenone itself (Barja, 1999).

Al the level of complex III, where it appears to be located the main capability of mitochondria to generate ROS, the transference of electrons follows the paths shown in the schema of Fig. 4 where the most common inhibitors of complex III are also indicated. Ubiquinone (UQ) receives two electrons from complex I or complex II and becomes fully reduced to ubiquinol $\left(\mathrm{UQH}_{2}\right)$ which transfers a single electron to the iron-sulfur complex of cytochrome reductase and becomes transformed in the radical ubisemiquinone $\left(\mathrm{UQH}^{\bullet}\right)$. Ubisemiquinone can generate superoxide because it can transfer the electron to molecular $\mathrm{O}_{2}$ to generate $\mathrm{O}_{2}{ }^{\bullet-}$. Normally two molecules of $\mathrm{UQH}^{\bullet}$ are recycled to one molecule of ubiquinone and to other of ubiquinol with the cooperation of the two cytochrome $b$ components. Myxothiazol and stimagtellin inhibit the transference of electrons to the

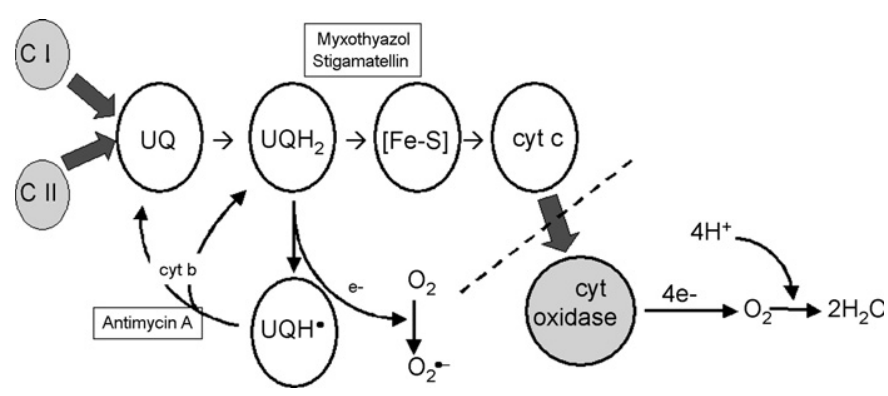

Fig. 4. Transference of electrons within complex III and location of the action of most commonly used inhibitors of this complex (see text). 
iron-sulfur complex and maintain the quinone in its reduced stable state $\left(\mathrm{UQH}_{2}\right)$ and should tend to decrease the production of $\mathrm{O}_{2}{ }^{\bullet-}$ (Chandel et al., 1998); on the contrary, antimycin A forces the accumulation of $\mathrm{UQH}^{\bullet}$ and therefore the generation of $\mathrm{O}_{2}{ }^{\bullet-}$, but again myxothiazol blocks antimycin generation of ROS (Votyakova and Reynolds, 2001). It should be mentioned however that other authors have also found that myxothiazol at low concentrations $(<0.6 \mu \mathrm{M})$, alike those used by Chandel et al. (1998), did not modified the rate of ROS production by hepatocytes or mitochondria, while higher concentrations $(>5 \mu \mathrm{M})$ drastically increased the rate of ROS production. This dose-dependence correlated with the inhibition of respiration in isolated hepatocytes or isolated liver mitochondria indicating that full inhibition of the respiratory chain at the level of complex III forces upstream electron transporters to become reduced and to generate ROS; flavoenzymes (including complexes I, II and electron transfer flavoprotein) were implicated in myxothiazol-induced ROS production because it was inhibited by diphenylene iodonium (Young et al., 2002). Stigmatellin did also produced minimal changes in ROS production assayed as decrease of aconitase activity (Muller et al., 2004).

The role of mitochondrial potential in the production of ROS is not always easy to delimit, because most frequently maneuvers addressed to alter the mitochondrial electrochemical potential are used in conjunction with other venoms acting at different levels. In the early seventies Boveris et al. (1972) and more recently Votyakova and Reynolds (2001) showed that incubation of mitochondria in the absence of ADP, a condition in which mitochondrial potential rises to a maximum (mitochondrial state 4 ), produced and released $\mathrm{H}_{2} \mathrm{O}_{2}$ and that this production vanished upon addition of ADP which allowed mitochondria to use their potential to synthesize ATP (i.e., bringing mitochondria to state 3). Several authors have found that in succinate-fed mitochondria the rotenone-sensitive reverse flow of electrons and genesis of ROS form complex II to complex I requires a high mitochondrial potential, and that uncouplers abolished most if not entirely this production (Votyakova and Reynolds, 2001); in malate/glutamate fed mitochondria rotenone increases in a dose dependent manner (albeit different than that required to inhibit respiration) the production of ROS, and a significant part of this production also was sensitive to uncouplers. Also in succinate-fed mitochondria, uncouplers strongly potentiate the antimycin-driven ROS production, this effect being apparently due to a facilitation of the oxidation of succinate to fumarate and the building up of very high fumarate to succinate ratios (Votyakova and Reynolds, 2001). Uncouplers per se did not alter (or did minimally) the rate of ROS production in isolated brain mitochondria (Votyakova and Reynolds, 2001) nor in synaptosomes (Sipos et al., 2003).

We think that it has been documented that mitochondria have the capabilities to generate $\mathrm{O}_{2}{ }^{\bullet-}$ when its functioning is altered with mitochondrial poisons. The point being, do they generate $\mathrm{O}_{2}{ }^{--}$in normal conditions in the absence of inhibitors? And more relevant for this article, do mitochondria increase their rate of production of $\mathrm{O}_{2}{ }^{\bullet-}$ in hypoxia? In looking the recordings from most of the articles quoted in preceding paragraphs, it is evident that in normal mitochondria or isolated cells before poisons are added the rate of ROS production is very low whether it is assessed as $\mathrm{H}_{2} \mathrm{O}_{2}$ release, with a fluorescent indicator, spin-trap methods or as the rate of mitochondrial aconitase inactivation. Yet, from the teleologically point of view it might be asked: if mitochondria do not produce ROS, why are they so well furnished with SOD, GPx and lipoic acid the most important ROS-defense mechanisms? Nohl et al. (2005) suggest that in physiological conditions mitochondria produce minimal (if at all) amounts of ROS, with most measurements of mitochondrial ROS production being artifacts derived from mitochondrial isolation procedures and techniques used for ROS measurement; they envision the strong anti-ROS armamentarium that mitochondria possess as a functional reserve to fight ROS in pathophysiological conditions. This last argument might be best understood if we think of phagocytic cells: they have great capabilities to generate ROS, and they do so in the pathophysiological situations of pathogen invasion, but physiologically they do not produce ROS at all. The most relevant question in the present context is the second one formulated at the outset of the paragraph, namely if hypoxia increases the rate of ROS production in cells in general and in CB chemoreceptor cells in particular. Schumacker group has championed the notion that hypoxia increases the rate of ROS production by mitochondria, i.e., hypoxia would represent one of those pathophysiological situations in which disturbance of mitochondrial functioning leads to overproduction of ROS (see above). The paradoxical situation is that at least for one of the preparations, pulmonary artery smooth muscle cells, Archer group claims the opposite, i.e., hypoxia decreases the rate of mitochondrial ROS production (Waypa and Schumacker, 2006 vs. Archer et al., 2006). Obviously, the physiological or pathophysiological truth should be single.

In chemoreceptor cells, the only measurement of ROS production has been performed by He et al. (2005; see Fig. 7 in Dinger et al., 2007). What we have observed using dihydroethidine as indicator of ROS production is that the time-dependent increase in fluorescence has a very small slope, indicative of a very small rate of ROS production by chemoreceptor cells in primary culture in our normoxia $\left(20 \% \mathrm{O}_{2}\right.$-equilibrated solutions; $P_{\mathrm{O}_{2}} \approx 120 \mathrm{mmHg}$ ), which in fact might well represent a certain level of hyperoxia. Lowering the $P_{\mathrm{O}_{2}}$ to $30-32 \mathrm{mmHg}$ (which inhibited $\mathrm{K}^{+}$currents and produced marked rises in intracellular $\mathrm{Ca}^{2+}$ ) did not alter that slope in chemoreceptor cells obtained from mice null to subunit 47phox of NADPH oxidase although it increased abruptly in wild type cells. This observation indicating that no other enzyme system in chemoreceptor cells except for NADPH oxidase, increased the rate of ROS production in response to hypoxia. Inhibition of mitochondrial complex IV produced a dramatic increase in the slope of the fluorescent signal, both, in control and 47phox null chemoreceptor cells. Fluorescent signal in chemoreceptor cells from wild type mice was sensitive to 4-(2-aminoethyl)-benzenesulfonyl fluoride, a specific NADPH oxidase inhibitor, was independent on the sampling rate (excluding light-induced artifacts; Hockberger et al., 1999) and specific for chemoreceptor cells, as neurons from the petrosal, nodose and sympathetic ganglion did not respond to hypoxia. Finally the quality of the knockouts and the overall 
recording system was assessed by the use of phagocytes (neutrophils) from $\mathrm{KO}$ and control mice: upon activation of these phagocytes a burst of fluorescence occurred in control cells, and no change in KO cells; the basal rate of ROS production in neutrophils was comparable to that observed in chemoreceptor cells, indicating once again the very limited production of ROS from any source in physiological conditions. Thus, levels of hypoxia capable of strongly activating chemoreceptor cells do not represent pathophysiological situations capable of altering the rate of mitochondrial ROS production. Does any level of hypoxia increase the mitochondrial rate of ROS production? According to Gnaiger et al. (2000), cytochrome oxidase, and its regulation machinery, is designed precisely to prevent an increase in ROS production until extremely low levels of oxygen. At $P_{\mathrm{O}_{2}}$ about $0.5 \mathrm{mmHg}$ respiration proceeds at nearly maximal rate, decreasing the production of mitochondrial $\mathrm{NO}^{\bullet}$ to nearly cero (given the much higher $K_{\mathrm{m}}$ of nitric oxide synthase than cytochrome oxidase for $\mathrm{O}_{2}$ ) and therefore minimizing the inhibition of cytochrome oxidase and according to Eq. (1) (see above) making very unlikely the formation of $\mathrm{O}_{2}{ }^{\bullet-}$. These considerations seem to conflict with the situation that occurs in solid fast-growing tumors where the angiogenesis process runs behind cell growth, and therefore intense hypoxic or anoxic environments are generated and yet an overproduction of ROS is well documented. This apparent conflict might be explained if it is considered that in cancer cells there is a very high rate of mitochondrial DNA mutations that lead to a mitochondrial function characterized by an inhibited oxidative phosphorylation and increased rate of ROS production (Brandon et al., 2006). The switch to glycolysis via HIF- $1 \alpha$-mediated induction of glycolytic enzymes would secure the energetic demands of cancer cells.

In a recent series of experiments in our laboratory (Obeso et al., 2006; manuscript in preparation), we have used different concentrations of rotenone, nitropropionic acid, antimycin A, sodium azide and dinitrophenol alone or in combination with $\mathrm{N}$-acetylcysteine and have determined the glutathione redox potential $\left(\mathrm{E}_{\mathrm{GSH}}\right)$, the ATP levels and the response of chemoreceptor cells assessed by their release of catecholamines. All mitochondrial poisons, except the uncoupler, caused marked decreases in $\mathrm{E}_{\mathrm{GSH}}$ and $N$-acetylcysteine reversed this effect of the mitochondrial poisons. All poisons, except for the uncoupler at low concentrations, caused a decrease in the ATP content of the $\mathrm{CB}$ and all poisons, except for nitropropionic acid the inhibitor of complex II, caused an strong activation of chemoreceptor cells, with $N$-acetylcysteine not changing the response of chemoreceptor cells. These findings would indicate that mitochondrial ROS are not responsible for the activation of chemoreceptor cells produced by the metabolic poisons. Nonetheless, they appear to have a common denominator, namely a decrease of the phosphate potential. Even if low concentrations of uncouplers do not decrease ATP levels, the exaggerated rate of glucose oxidation that they produce (Obeso et al., 1989) is triggered precisely by a decrease in the phosphate potential and a concomitant decrease in the NADH/NAD ${ }^{+}$ ratio (Obeso et al., 1997). Thus, in all situations it should be expected an increase in AMP levels, capable of activating AMP- dependent protein kinase and activation of chemoreceptor cells (see Evans, 2006).

\subsection{General reactivity of superoxide anion}

Superoxide radical can act both as a reducing and an oxidizing agent. Its reactivity determines its short life in biological fluids, although in reacting with some molecules it will generate new free radicals. $\mathrm{O}_{2}{ }^{\bullet-}$ can react with itself in such a manner that one of the $\mathrm{O}_{2}{ }^{\bullet-}$ is oxidized to $\mathrm{O}_{2}$ and the other is reduced to $\mathrm{H}_{2} \mathrm{O}_{2}$; this constitutes the spontaneous dismutation reaction. Mechanistically, the dismutation reaction in biological fluids occurs by protonation or one or both $\mathrm{O}_{2}{ }^{\bullet-}$ to $\mathrm{HO}_{2} \bullet$ and the spontaneous dismutation reaction proceeds in one of these two manners:

$$
\begin{aligned}
& \mathrm{HO}_{2}^{\bullet}+\mathrm{O}_{2}^{\bullet-}+\mathrm{H}^{+} \rightarrow \mathrm{H}_{2} \mathrm{O}_{2}+\mathrm{O}_{2} \quad\left(k_{2} \approx 10^{8} \mathrm{M}^{-1} \mathrm{~s}^{-1}\right) \\
& \mathrm{HO}_{2}^{\bullet}+\mathrm{HO}_{2}^{\bullet} \rightarrow \mathrm{H}_{2} \mathrm{O}_{2}+\mathrm{O}_{2} \quad\left(k_{2} \approx 10^{6} \mathrm{M}^{-1} \mathrm{~s}^{-1}\right)
\end{aligned}
$$

In addition to spontaneous dismutation, there is a group of enzymes, superoxide dismutases which are specifically devoted to eliminate $\mathrm{O}_{2}{ }^{\bullet-}$. SOD was discovered as an erythrocuprein with enzymatic activity (see Halliwell and Gutteridge, 1999) devoted specifically (no other substrates than $\mathrm{O}_{2}{ }^{\bullet-}$ are known for SOD) to oxygen free-radical metabolism; the discovery, i.e., the existence of defensive enzymatic systems to dispose $\mathrm{O}_{2}{ }^{\bullet-}$, settled the concept of the superoxide theory of oxygen toxicity. SOD are metalloproteins that contain transition metals, copper, manganese or iron which sequentially accept one electron from $\mathrm{O}_{2}{ }^{\bullet-}$ to oxidize it to $\mathrm{O}_{2}$ an donate one electron to reduce $\mathrm{O}_{2}{ }^{\bullet-}$ to $\mathrm{H}_{2} \mathrm{O}_{2}$ according to the reaction (for manganese containing SOD):

Enz- $-\mathrm{Mn}^{3+}+\mathrm{O}_{2}{ }^{\bullet-} \rightarrow$ Enz-$-\mathrm{Mn}^{2+}+\mathrm{O}_{2}$

Enz- $\mathrm{Mn}^{2+}+2 \mathrm{H}^{+}+\mathrm{O}_{2}{ }^{--} \rightarrow$ Enz- $-\mathrm{Mn}^{3+}+\mathrm{H}_{2} \mathrm{O}_{2}$

There are several SOD, the most important being mitochondrial SOD which is a manganese SOD and cytoplasmic SOD which is a copper-zinc SOD that is also present also in lysosomes, nucleus, peroxisomes and intermembrane space in mitochondria (in copper-zinc SOD, zinc serves a non-catalytic enzyme-stabilizing function); this location of copper-zinc SOD is very important because a significant fraction of the $\mathrm{O}_{2}{ }^{\bullet-}$ generated in the mitochondria (complex III) escape to the intermembrane space and therefore its ability to reach cytoplasm components is greatly diminished (Muller et al., 2004). There are other minor forms of copper-zinc SOD in extracellular fluids, and in bacteria there are also two forms of iron SOD.

Superoxide can reduce some transition metal containing proteins (e.g., cytochrome $c$ ). Particularly relevant reactions of $\mathrm{O}_{2}{ }^{\bullet-}$ with transition metals occur on iron-sulfur clusters existing in several enzymes and electron transport carriers in the respiratory chain, best exemplified by the reaction with mitochondrial aconitase, although the susceptibility of sulfur-iron clusters to $\mathrm{O}_{2}{ }^{\bullet-}$ depends on its intimate molecular structure and grade of exposure to the mitochondrial matrix. Both cytoplasmic and mitochondrial aconitases contain $[4 \mathrm{Fe}-4 \mathrm{~S}]^{2+}$ clusters 
and in both $\mathrm{O}_{2}{ }^{\bullet-}$ can promote their inactivation on promoting the loss of an iron atom and formation of $\mathrm{H}_{2} \mathrm{O}_{2}$ according to the reaction:

$$
[4 \mathrm{Fe}-4 \mathrm{~S}]^{2+}+2 \mathrm{H}^{+}+\mathrm{O}_{2} \bullet-\rightarrow[3 \mathrm{Fe}-4 \mathrm{~S}]^{1+}+\mathrm{Fe}^{2+}+\mathrm{H}_{2} \mathrm{O}_{2}
$$

Aside from the biological consequences that we will discuss below, inactivation of either form of aconitase can help to trace the origin, mitochondrial or cytoplasmic, of $\mathrm{O}_{2}{ }^{\bullet-}$ (Han et al., 2005) in any given situation (although escape of part of mitochondrially generated $\mathrm{O}_{2}{ }^{\bullet-}$ to the cytoplasm can blur the situation). For example, Kumar et al. (2006) have observed that intermittent hypoxia caused a preferential decrease in the activity of mitochondrial aconitase suggesting that the main locus of $\mathrm{O}_{2}{ }^{\bullet-}$ generation in these situations is mitochondria. Obviously, inactivation of mitochondrial aconitase leads to a decrease in the Krebs activity with the subsequent impairment of energy production. However, the extension of damage depends on several factors (Han et al., 2005): (a) activity of mitochondrial SOD, as for example null mice for mitochondrial SOD exhibited marked reduction (in comparison to controls) in the activity of aconitase as well in the iron-sulfur containing respiratory complexes I and II-III; (b) abundance of iron-sulfur enzymes (varies from tissue to tissue); and (c) the concentration of citrate which is protective and the presence of $\mathrm{NO}^{\bullet}$. $\mathrm{NO}^{\bullet}$ can react with $\mathrm{O}_{2}{ }^{\bullet-}$ to form peroxynitrite (at a nearly diffusion controlled rate; $\mathrm{ONOO}^{-}$; see below) which is very strong oxidant and nitrating agent capable of attacking the iron-sulfur clusters, nitrating tyrosine residues and oxidizing cysteine residues, and indeed producing loss of aconitase activity and other iron-sulfur clustercontaining enzymes (Han et al., 2005). It should be recalled that mitochondrial nitric oxide synthase generates $\mathrm{NO}^{\bullet}$ and therefore the formation of $\mathrm{ONOO}^{-}$is favored; in fact it has been estimated that $15 \%$ of the $\mathrm{O}_{2}{ }^{\bullet-}$ generated by mitochondria ends up as $\mathrm{ONOO}^{-}$and the reaming $85 \%$ as $\mathrm{H}_{2} \mathrm{O}_{2}$, generated by mitochondrial SOD, oxidation of iron-sulfur clusters and probably by reactions with other antioxidant molecules located in the mitochondrial interior. An additional source of potential mitochondrial damage derives from the co-release of $\mathrm{Fe}^{2+}$ and $\mathrm{H}_{2} \mathrm{O}_{2}$ which can initiate the genesis of the most devastating $\mathrm{OH}^{\bullet}$ radical via the Fenton reaction (see below).

Superoxide anion or its protonated form $\mathrm{HO}_{2}{ }^{\bullet}$ can react with other free radicals, as for example nitric oxide $\mathrm{NO}^{\bullet}$ to yield peroxynitrite $\left(\mathrm{O}_{2}^{\bullet-}+\mathrm{NO}^{\bullet} \rightarrow \mathrm{ONOO}^{-}\right)$. Peroxynitrite $-\mathrm{O}-\mathrm{O}-\mathrm{N}=\mathrm{O}$ being a much more reactive isomer of nitrate. This reactivity between $\mathrm{O}_{2}{ }^{\bullet-}$ and $\mathrm{NO}^{\bullet}$ implies that if simultaneously present in biological systems each radical can neutralize each other, lessening the biological activity of $\mathrm{NO}^{\bullet}$ and the unwanted effects of $\mathrm{O}_{2}{ }^{\bullet-}$. In this regard it has been suggested that excess $\mathrm{O}_{2}{ }^{\bullet-}$ production in damaged endothelium (e.g., in atherosclerosis or chronic subclinical infections) would facilitate the genesis of hypertension by neutralizing naturally produced vasodilator $\mathrm{NO}^{\bullet}$ (Harrison, 1994). Consequently, the addition of superoxide dismutase mimetics such as Manganese (III) tetrakis(1-methyl4-pyridyl)porphyrin pentachloride on destroying $\mathrm{O}_{2}{ }^{\bullet-}$ would enhance the activity of naturally produced $\mathrm{NO}^{\bullet}$ as originally shown with the addition of natural superoxide dismutase by
Moncada and coworkers in aortic muscle strips (Gryglewski et al., 1986). In the case of the CB chemoreceptors those dismutase mimetics would lead to increased $\mathrm{NO}^{\bullet}$ and inhibition of $\mathrm{CB}$ activity (Summers et al., 1999). The production of $\mathrm{O}_{2}{ }^{\bullet-}$ and $\mathrm{NO}^{\bullet}$ in mitochondria matrix would account for the more frequent mitochondrial than nuclear DNA damage in aging, cancer and neurodegenerative diseases (Brandon et al., 2006). On the other hand, nitrosylation of tyrosine in proteins can distort their structures leading to abnormal signaling, loss of enzymatic activity (e.g., ribonucleotide reductase or aconitase) and abnormal cell cytoskeleton formation.

\section{Heme oxygenases, the biliverdin-bilirubin cycle and oxygen chemoreception}

We include this section in our article by two reasons: first, because heme oxygenases ( $\mathrm{HO}$; specifically the isoform $\mathrm{HO}-2$ ) has been suggested to participate in oxygen sensing (Williams et al., 2004; Kemp et al., 2006), and second, because HO on degrading free heme groups generate biliverdin which is enzymatically reduced to bilirubin, being bilirubin an scavenger of ROS of apparently a major quantitave importance in some (or all) mammalian cells (Baranano et al., 2002; Sedlak and Snyder, 2004; Ryter et al., 2006).

\subsection{The antioxidant power of the biliverdin-bilirubin cycle}

Heme oxygenases (HO-1, HO-2) catalyze the rate-limiting step in the conversion of heme to the bile pigments (biliverdin and bilirubin) and constitute a major intracellular source of free iron, $\mathrm{CO}$ and bilirubin. We have been referring to free iron and its potential damaging effect due to its participation in the genesis of $\mathrm{OH}^{\bullet}$ radicals via Fenton reaction. In fact, overexpression of $\mathrm{HO}$ in HeLa caused a marked sensitivity to ultraviolet light radiation and cell death that was due to the release of iron because an iron chelator eliminated it (Kvam et al., 2000). However, iron released from $\mathrm{HO}$ activity binds to iron regulatory protein to stimulate ferritin synthesis, which provides an iron detoxification mechanism, and therefore the damaging effects are minimized. In fact, in a recent review from the same laboratory (Ryter et al., 2006), it is proposed that the dominant prooxidant effects of $\mathrm{HO}$ is only seen in systems where the enzyme is overexpressed and cells are fed with exogenous heme, and it is concluded that in any cell system using endogenous heme, even when HO-1 (the inducible form of HO) is upregulated, the net effect resulting from $\mathrm{HO}$ activity is antioxidant. This antioxidant effect depends on the so-called biliverdin-bilirubin cycle. HO-1 is highly expressed in tissues directly involved in erythrocyte or hemoglobin metabolism (spleen and reticuloendothelial cells of the liver and bone marrow), but in most other tissues, HO-1 occurs at very low levels in normal conditions, but it is rapidly induced under a variety of stresses, particularly under situations that involve oxidative stress (Noriega et al., 2002); sustained hypoxia also induced HO-1 in cultured cardiomyocytes (Kacimi et al., 2000) and in rat CB when the animals where breathing in a $10 \%$ atmosphere during 8 days (Caceres et al., 2006). HO-2 is constitutively expressed ubiquitously and 


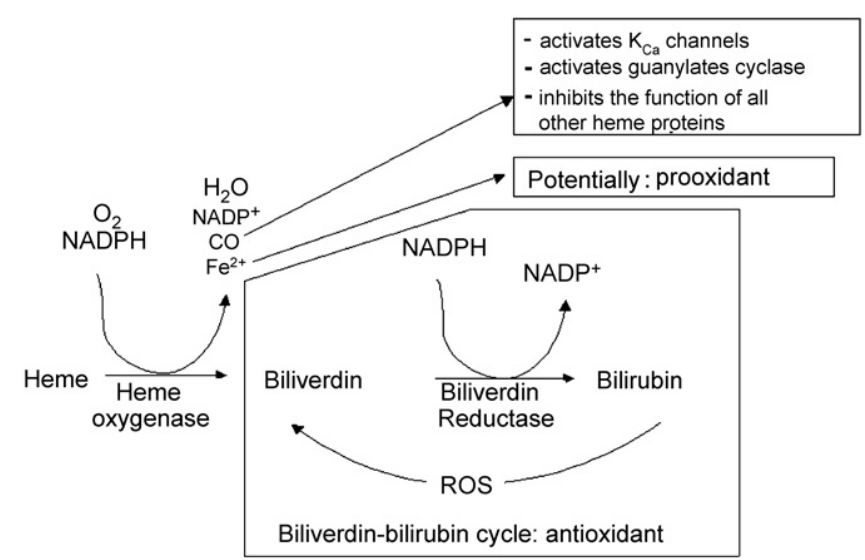

Fig. 5. Heme oxygenase degradation of heme groups. Three of the products of HO degrading reactions exhibit important physiological and pathophysiological functions, which are grouped in boxes. In the text is provided a brief account of those functions.

its expression is not regulated by environmental stresses. Both isoforms are preferentially located in the endoplasmic reticulum, but other subcellular locations including nuclear membrane and plasma membrane, particularly associated to caveolae have been described. In addition, it appears that under stressfull conditions when HO-1 is induced it might also be localized in the mitochondrial compartment (Ryter et al., 2006).

The participation of both $\mathrm{HO}$ as defense mechanisms against oxidant stress comes from the rapid induction in response to oxidant insults in the case of $\mathrm{HO}-1$, and in the case of HO-2 it is implied from studies showing that middle cerebral artery ligation produced more intense stroke damage in HO-2 null mice than in control animals (Sedlak and Snyder, 2004). The antioxidant mechanism of $\mathrm{HO}$ resides in the redox cycle that their main catabolic product, biliverdin, can undergo (Fig. 5). Sedlak and Snyder (2004) argue that at the first sight the conversion of biliverdin to bilirubin appears as an energetic waste: first, because it requires equivalent of reductions, and thereby cell nutrient utilization and, second, because bilirubin being poorly soluble (contrary to biliverdin), needs to be glucuronidated in the liver to be facilitate its excretion, a reaction that is also energetically costly. Apparently, it was this line of thinking that drove to search for a function for bilirubin and the function is its ROS scavenging capacity. Bilirubin is capable of reacting with a great variety of ROS and RNS, and given its lipid solubility, it seems to greatly contribute (in conjunction with ascorbic and lipoic acid, see above) to regenerate oxidized Vitamin E and to prevent lipid peroxidation. Some authors (Baranano et al., 2002) have obtained evidence that would suggest that the biliverdin/biliverdin reductase/bilirubin cycle is physiologically more potent than the correspondent GSH/glutathione reductase/GSSG cycle, because silencing the biliverdin reductase with siRNA techniques produced a higher rate of death of their HeLa cultured cells, than nearly fully depleting GSH levels by inhibition of its synthesis. In addition, it is well known that bilirubin conjugated with albumin is capable of eliminating ROS in blood, and in addition conjugation itself prevents the entrance of bilirubin in brain where it is extremely toxic.
Although there are no literature studies directly linking bilirubin and GSH metabolisms, there are in vitro data indicating that bilirubin can react with nitrosylated compounds such as $S$ nitroglutathione and $S$-nitrocysteine, and therefore it can protect cells against NO` and RNS damage (Mancuso et al., 2003).

\subsection{Carbon monoxide, ion channels and oxygen chemoreception}

The last product of $\mathrm{HO}$ to be discussed is $\mathrm{CO}$. Carbon monoxide has a much lower reactivity in biological systems that their counterparts diatomic $\mathrm{O}_{2}$ and $\mathrm{NO}^{\bullet}$. It can bind to form complexes with a great number of metalloproteins, particularly with hemoproteins, but this interaction does not imply chemical transformation of CO. Result of those interactions is the activation of the function of some of them (e.g., guanylate cyclase, cycloxygenase?) but in most cases the proteins that bind $\mathrm{CO}$ lose their physiological function (hemoglobin, myoglobin, cytochrome $a$, cytochromes P450, tryptophane hydroxylase), and this lost of function is responsible for the toxic effects of $\mathrm{CO}$. The physiological effects of $\mathrm{CO}$ have been related to its endogenous production from basal (HO-2) and inducible $\mathrm{HO}$ (HO-1) activity, and probably the main target of $\mathrm{CO}$ is soluble guanylate cyclase (Ryter et al., 2006) and certain Kv (Lopez-Lopez and Gonzalez, 1992) and maxi-K ${ }^{+}$channels (Riesco-Fagundo et al., 2001); in these physiological actions $\mathrm{CO}$ is an activator. Through its interaction with guanylate cyclase it produces an increase in cGMP and thereby it behaves alike $\mathrm{NO}^{\bullet}$, i.e., $\mathrm{NO}^{\bullet}$ and $\mathrm{CO}$ are physiological endothelial-derived relaxing factors for blood vessels in most vascular beds, both seem to act as neurotransmitters or cotransmitters in central and peripheral nervous system and both participate in smooth muscle relaxation in the gastrointestinal tract (Sanders and Koh, 2006). But it should be kept in mind that $\mathrm{NO}^{\bullet}$ is very reactive and that RNS are toxic, while $\mathrm{CO}$ as stated above is unreactive and it is disposed throughout its binding to hemoglobin and elimination in the respiratory system (although apparently a minor proportion can be oxidized to $\mathrm{CO}_{2}$ by cytochrome oxidase; $\mathrm{Wu}$ and Wang, 2005). However, the dilating actions of $\mathrm{CO}$ (and $\mathrm{NO}^{\bullet}$ ) are not solely due to activation of guanylate cyclases and the subsequent transduction cascade (Ryter et al., 2006) can also be directly produced by their direct interactions with ion channels, particularly with maxi-K channels.

In addition to the well-established interaction of $\mathrm{CO}$ with maxi-K channels, there is also some evidences suggesting that $\mathrm{CO}$ interacts with other channel types, including sodium channels, calcium channels, some $\mathrm{Kv}$ channels and $\mathrm{K}_{\mathrm{ATP}}$ channels. Some of these potential targets of $\mathrm{CO}$ are expressed in chemoreceptor cells and thereby we will deal with them in some detail in the paragraphs that follow.

The interactions of $\mathrm{CO}$ with sodium channel appear to be mostly developmental as perinatal exposure $\mathrm{CO}$ causes permanent alterations in the kinetic and ion selectivity properties of the channels, being suggested that $\mathrm{CO}$ probably changes the membrane lipid environment (Moxness et al., 1996) with the ensuing shifts in activation and inactivation voltages. These effects would have interest mostly from a toxicological perspective. 
The role of $\mathrm{CO}$ in regulating $\mathrm{Ca}^{2+}$ channels is controversial with some authors finding that it activates them, others that inhibits them and some other authors finding that it does not have any effect. Probably, the discrepancies might results from genuine tissue specific differences. For example, Linden et al. (1993) found in a pituitary cell line that presumed inhibition of HO-2 with $\mathrm{Zn}$-protoporphyrin attenuated irreversibly all subtypes of voltage operated $\mathrm{Ca}^{2+}$ channels, with a $62 \%$ inhibition of peak $\mathrm{Ca}^{2+}$ current at $5 \mu \mathrm{M}$; this inhibition was fully prevented by bath application of SOD, and therefore they attributed their observation to the genesis of $\mathrm{O}_{2}{ }^{\bullet-}$ produced by $\mathrm{Zn}$-protoporphyrin instead of HO-2 inhibition and decrease in $\mathrm{CO}$ production. The findings and conclusions of Prabhakar's laboratory in chemoreceptor cells (reviewed by Prabhakar, 1998) are at variance with those of Linden et al. (1993). First, Prabhakar and colleagues found that $1-3 \mu \mathrm{M} \mathrm{Zn}$-protoporphyrin increased $\mathrm{Ca}^{2+}$ currents in 2 cells and was without effect in three cells and consistent with this observation they also found that the HO-2 inhibitor applied during 5 min caused an increase in intracellular $\mathrm{Ca}^{2+}$ levels in 54 out of 99 cells. And second, they concluded that the effects were due to the decrease in $\mathrm{CO}$ production subsequent to HO-2 inhibition. The overall conclusion of Prabhakar studies was that $\mathrm{CO}$ would physiologically be inhibiting chemoreceptor activity, being the inhibition mediated, at least in part, by reduction of $\mathrm{Ca}^{2+}$ currents. This conclusion is consistent with previous observations of the same laboratory (Prabhakar et al., 1995) showing that the same HO inhibitor $(3 \mu \mathrm{M})$ caused a delayed $(\approx 10 \mathrm{~min})$ increase in nine cat carotid body preparations, with technical problems impeding to see the excitatory action in four preparations; additionally, in the same article it was shown that chemoreceptor cells from both rat and cat were intensely positive to HO-2 but negative to HO-1. Recently, working with rat $\mathrm{CB}$, we have found immunocytochemically both $\mathrm{HO}$ isoforms in tyrosine hydroxylase positive chemoreceptor cells, and additionally that HO-2 is transcribed at a very slow rate in comparison to HO-1 (based on the threshold cycle for each gen in relative quantification studies in our qPCR system; Caceres, Rocher and Gonzalez, unpublished). Finally, variable effects of $\mathrm{CO}$ on $\mathrm{Ca}^{2+}$ currents mediated by soluble guanylate cyclase have also been described (see Wu and Wang, 2005).

Although not directly recorded, $\mathrm{K}_{\text {ATP }}$ channels also appear to be targets of CO. Thus, an artificial CO-donor produced a dose dependent relaxation of phenylephrine-precontracted aorta rings that was partially prevented by prior treatment with $\mathrm{K}_{\mathrm{ATP}}$ channels blocker glibenclamide (Foresti et al., 2004).

As early as 1992 we (Lopez-Lopez and Gonzalez, 1992) obtained clear evidence that $\mathrm{CO}(10 \% \mathrm{CO}$ in nitrogen) was able to prevent and to reverse the inhibition of $\mathrm{K}^{+}$currents produced by hypoxia $\left(5 \% \mathrm{O}_{2}\right.$ in nitrogen). Since $\mathrm{O}_{2}$-sensitive channels in rabbit chemoreceptor cells are $\mathrm{Kv} 4$, in all likelihood $\mathrm{Kv} 4.3$ (Sanchez et al., 2002), we infer that this channel is responsive to CO. It is needed to state that we did not envision the CO effect as a direct action on the channel, rather we hypothesized that $\mathrm{CO}$ was acting at a putative hemoprotein $\mathrm{O}_{2}$-sensor coupled in an unknown manner to the channel. We have maintained this concept of an independent $\mathrm{O}_{2}$-sensor because in cotransfection experiments we found that $\mathrm{Kv} 4.2$ only acquired $\mathrm{O}_{2}$-sensing properties if coexpressed with the regulatory $\mathrm{Kv} \beta-2$ subunit, being the cotransfected preparations not only sensitive to low $P_{\mathrm{O}_{2}}$ but also sensitive to CO (Perez-Garcia et al., 1999). Our findings on the role of regulatory $\beta$ subunits, which has been supported by findings in pulmonary vessels (Coppock and Tamkun, 2001 ), the diversity of $\mathrm{K}^{+}$channels sensitive to hypoxia and the apparent absence of motifs in the diverse channel proteins to interact with $\mathrm{O}_{2}$ has lead us to maintain the notion of an independent $\mathrm{O}_{2}$-sensor capable of interacting with the channels with the needed cooperation of regulatory subunits (but see below).

The regulation of maxi-K channels by $\mathrm{CO}$ comes from fields different than chemoreception. In the rat tail artery it was shown that part of the relaxation in phenylephrine precontracted strips produced by $\mathrm{CO}$ was endothelium independent and sensitive to charibdotoxin implying that it was due to maxi-K activation (see Wu and Wang, 2005). The same authors working with isolated smooth muscle cells of the same tail artery preparation showed in inside-out patches that $\mathrm{CO}$ increased the opening probability of maxi-K, and by chemically manipulating histidine residues in the external surface of the membrane, the authors concluded that $\mathrm{CO}$ interacted directly with histidine residues of the maxi-K channel protein (see Wu and Wang, 2005). In additional experiments using full pharmacological activation of maxi-K regulatory $\beta$ subunits and transfection of maxi-K $\alpha$ subunits in HEK cells the authors concluded that the regulatory subunits were not necessary to obtain the stimulatory effect of CO (see Wu and Wang, 2005). Comparable results have been obtained by Xi et al. (2004) in native and cotransfected channels, finding additionally that $\mathrm{CO}$ shifted to the left the $\mathrm{Ca}^{+}$-dependent activation of maxi-K channel $\alpha$ subunits. In our laboratory (Riesco-Fagundo et al., 2001) working in whole-cell and inside-out patches of rat chemoreceptor cells we have shown that hypoxia reversibly decreases the opening probability of maxi-K, with $\mathrm{CO}$ fully reversing hypoxic channel inhibition; we concluded, first, that $\mathrm{O}_{2}$ and $\mathrm{CO}$ interaction with maxi-K channels does not require cytoplasmic mediators and second, that such interaction could be mediated by a membrane hemoprotein that would represent the putative $\mathrm{O}_{2}$ sensor previously proposed to exist. Additionally, in the same study we observed that ditiothreitol (a reducing agent) produced the opposite effect than hypoxia (i.e., increased the opening probability of the channel) while the oxidant agent $2,2^{\prime}$-dithiopyridine decreased channel activity; yet the redox status of the channels left hypoxic inhibition essentially intact in the two environments. Although not directly addressed in our study the role of $\beta$ subunits, we want to point out that rat $\mathrm{CB}$ expresses maxi-K $\beta-1, \beta-2$ and $\beta-4$ subunits (Caceres et al., 2006).

In a recent work, Williams et al. (2004; see Kemp et al., 2006) working with HEK cells stably transfected to express maxi $\mathrm{K} \alpha$ and $\beta$ subunits and constitutively expressing $\mathrm{HO}-2$ have shown that both components (the channel subunits and the enzyme) coprecipitate. Additionally, they showed that a chemical donor of $\mathrm{CO}$ dramatically increased the activity of the channel in inside-out patches, and that activation was mimicked while recording in normoxic conditions $\left(P_{\mathrm{O}_{2}}\right.$ around $150 \mathrm{mmHg}$ ) by co-application to the patches the substrates of HO-2 (NADPH and heme), but was absent in hypoxic conditions 
$\left(P_{\mathrm{O}_{2}}\right.$ of $\left.10-15 \mathrm{mmHg}\right)$. When they switched from the heterologous system to rat chemoreceptor cells they found that hypoxia decreased the opening probability of maxi-K in a reversible manner (as we have previously been shown, see Riesco-Fagundo et al., 2001). The authors also claim that addition of HO-2 substrates to solutions bathing the chemoreceptor cells inside-out patches increased the opening probability of maxi-K channels in normoxia and augmented hypoxic inhibition; however, from their summary data, it appears that neither of these two effects of HO-2 substrates reached statistical significance. With those findings they proposed that HO-2 is who confers the sensitivity of maxi-K to hypoxia: in normoxia, when HO-2 activity is high due to the $\mathrm{O}_{2}$ availability, the activity of maxi-K is high due to the $\mathrm{CO}$ activating properties of maxi-K while in hypoxia the $\mathrm{O}_{2}-$ lack lessens the generation of $\mathrm{CO}$ and a decrease in the maxi-K channel activity ensues. They also propose that the increased maxi-K inhibition observed in chemoreceptor cells upon addition of heme and NADPH, the substrates of HO-2, could be due to a direct inhibition of heme which has been shown to bind to and inhibit maxi-K (Tang et al., 2003; Horrigan et al., 2005). Regarding the precise location of $\mathrm{CO}$ interaction with maxi-K the authors of these studies favor the proposal made by $\mathrm{Wu}$ and Wang (2005; see above), i.e., some histidine residue in the $\alpha$ subunit of the channel. Although an immediate question comes to our mind, i.e., if we have a "locus" for $\mathrm{CO}$ to act would not the same "locus" be shared with $\mathrm{O}_{2}$ ? and if so, why we do need the HO-2 and $\mathrm{CO}$ at all? $\mathrm{O}_{2}$ and $\mathrm{CO}$ maintain maxi-K open, in normoxia we have $\mathrm{O}_{2}$ and $\mathrm{CO}$ and in hypoxia we have neither of them. Might be that we are dealing with redundant mechanisms so common in most biological processes. However, there are additional data indicating that $\mathrm{CO}$ and $\mathrm{O}_{2}$ can act at different "loci". Thus, in a recent study McCartney et al. (2005) have provided evidence that CO is capable of interacting with all isoforms of maxi-K, while sensitivity to hypoxia is conferred by a highly conserved motif within an alternatively spliced cysteine-rich insert stress-regulated exon (STREX), within the intracellular $\mathrm{C}$ terminus of $\alpha$ subunit of the channel. There are two recent studies (Zhang et al., 2006; Ortega-Saenz et al., 2006) that question a role for $\mathrm{HO}-2$ in $\mathrm{O}_{2}$-sensing in the $\mathrm{CB}$ chemoreceptor cells. The Japanese study found that null mice for HO-2 present a certain level of systemic hypoxemia that was attributed to lung ventilation-perfusion mismatching and normal ventilation in normoxia and a blunted ventilatory response to hypoxia (see Gonzalez, 2006). These findings are clearly opposite to the above mentioned observations of Prabhakar et al. (1995) using inhibitors of $\mathrm{HO}-2$, and certainly contrary to the expectations derived from the cellular and molecular studies of Kemp's laboratory. In the study of Sevillian group found that in null mice to HO-2 the sensitivity to hypoxia of CB is remarkably similar to that seen in their wild type controls, leading them to conclude that HO-2 is not a $\mathrm{CB}$ chemoreceptor cell $\mathrm{O}_{2}$ sensor. A possible explanation for these apparently contradictory data could reside in the nature of the $\mathrm{O}_{2}$-sensitive $\mathrm{K}$ channels in mouse chemoreceptor cells, that appear to belong to the Kv3 family (Perez-Garcia et al., 2004), although as mentioned above we have found that up to $70 \%$ of the hypoxic sensitive current in mice chemoreceptor cells is iberiotoxin sensitive (He et al.,
2005; see also Otsubo et al., 2006 for possible strain differences). Just to finish the article, we want to mention that Otsubo et al. (2006) have presented preliminary evidence indicating that the ratio of $\alpha / \beta$ subunits of maxi $\mathrm{K}$ in two stains of mice, one ventilating normally to hypoxia and the other expressing a blunted hypoxic response, are very different, indicating that the ratio of $\alpha / \beta$ complexes might be crucial to set the level of hypoxic sensitivity.

\section{Acknowledgements}

The work was supported by DGICYT Grants BFU200406394 and BFI2003-01627, by ICiii grants PI042462 and CIBER CB06/06/0044 and by JCyL grants VA011C05 and VA106A05.

\section{References}

Archer, S.L., Michelakis, E.D., Thebaud, B., Bonnet, S., Moudgil, R., Wu, X.C., Weir, E.K., 2006. A central role for oxygen-sensitive K+ channels and mitochondria in the specialized oxygen-sensing system. Novartis Found Symp. 272, 157-171.

Baranano, D.E., Rao, M., Ferris, C.D., Snyder, S.H., 2002. Biliverdin reductase: a major physiologic cytoprotectant. Proc. Natl. Acad. Sci. USA 99, 16093-16098.

Barja, G., 1999. Mitochondrial oxygen radical generation and leak: sites of production in states 4 and 3, organ specificity, and relation to aging and longevity. J. Bioenerg. Biomembr. 31, 347-366.

Benov, L., Sztejnberg, L., Fridovich, I., 1998. Critical evaluation of the use of hydroethidine as a measure of superoxide anion radical. Free Radic. Biol. Med. 25, 826-831.

Boveris, A., Oshino, N., Chance, B., 1972. The cellular production of hydrogen peroxide. Biochem. J. 128, 617-630.

Brandon, M., Baldi, P., Wallace, D.C., 2006. Mitochondrial mutations in cancer. Oncogene 25, 4647-4662.

Buckler, K.J., Williams, B.A., Orozco, R.V., Wyatt, C.N., 2006. The role of TASK-like $\mathrm{K}^{+}$channels in oxygen sensing in the carotid body. Novartis Found Symp. 272, 73-85.

Caceres, A.I., Rocher, A., Gonzalez, C., 2006. Expression of heme oxygenases and maxi- $\mathrm{k}^{+}$alpha and beta subunits in the rat carotid body in normoxia and in chronic hypoxia. 5th Forum of European Neuroscience, Abstract 146.4.

Chance, B., Sies, H., Boveris, A., 1979. Hydroperoxide metabolism in mammalian organs. Physiol. Rev. 59, 527-605.

Chandel, N.S., Maltepe, E., Goldwasser, E., Mathieu, C.E., Simon, M.C., Schumacker, P.T., 1998. Mitochondrial reactive oxygen species trigger hypoxiainduced transcription. Proc. Natl. Acad. Sci. USA 95, 11715-11720.

Chen, Y.R., Chen, C.L., Zhang, L., Green-Church, K.B., Zweier, J.L., 2005. Superoxide generation from mitochondrial NADH dehydrogenase induces self-inactivation with specific protein radical formation. J. Biol. Chem. 280 (45), 37339-37348.

Ciccoli, L., Rossi, V., Leoncini, S., Signorini, C., Blanco-Garcia, J., Aldinucci, C., Buonocore, G., Comporti, M., 2004. Iron release, superoxide production and binding of autologous IgG to band 3 dimers in newborn and adult erythrocytes exposed to hypoxia and hypoxia-reoxygenation. Biochim. Biophys. Acta 1672, 203-213.

Coppock, E.A., Tamkun, M.M., 2001. Differential expression of K(V) channel alpha- and beta-subunits in the bovine pulmonary arterial circulation. Am. J. Physiol. Lung Cell Mol. Physiol. 281, L1350-L1360.

Cross, A.R., Jones, O.T., 1991. Enzymic mechanisms of superoxide production. Biochim. Biophys. Acta 1057, 281-298.

Dinger, B., He, L., Chen, J., Liu, X., Gonzalez, C., Obeso, A., Sanders, K., Hoidal, J., Stensaas, L., Fidone, S., 2007. The role of NADPH oxidase in carotid body arterial chemoreceptors. Respir. Physiol. Neurobiol. 157, $45-54$. 
Duranteau, J., Chandel, N.S., Kulisz, A., Shao, Z., Schumacker, P.T., 1998. Intracellular signaling by reactive oxygen species during hypoxia in cardiomyocytes. J. Biol. Chem. 273, 11619-11624.

Evans, M.A., 2006. AMP-activated protein kinase and the regulation of $\mathrm{Ca}^{2+}$ signalling in $\mathrm{O}_{2}$-sensing cells. J. Physiol. 574, 113-123.

Foresti, R., Hammad, J., Clark, J.E., Johnson, T.R., Mann, B.E., Friebe, A., Green, C.J., Motterlini, R., 2004. Vasoactive properties of CORM-3, a novel water-soluble carbon monoxide-releasing molecule. Br. J. Pharmacol. 142, $453-460$.

Ganfornina, M.D., Perez-Garcia, M.T., Gutierrez, G., Miguel-Velado, E., LopezLopez, J.R., Marin, A., Sanchez, D., Gonzalez, C., 2005. Comparative gene expression profile of mouse carotid body and adrenal medulla under physiological hypoxia. J. Physiol. 566, 491-503.

Geiszt, M., 2006. NADPH oxidases: new kids on the block. Cardiovasc. Res. 71 (2), 289-299.

Gnaiger, E., Mendez, G., Hand, S.C., 2000. High phosphorylation efficiency and depression of uncoupled respiration in mitochondria under hypoxia. Proc. Natl. Acad. Sci. USA 97, 11080-11085.

Gonzalez, C., 2006. Concluding remarks. Adv. Exp. Med. Biol. 580, 351-359.

Gonzalez, C., Almaraz, L., Obeso, A., Rigual, R., 1994. Carotid body chemoreceptors: from natural stimuli to sensory discharges. Physiol. Rev. 74, 829-898.

Gonzalez, C., Sanz-Alfayate, G., Agapito, M.T., Gomez-Nino, A., Rocher, A., Obeso, A., 2002. Significance of ROS in oxygen sensing in cell systems with sensitivity to physiological hypoxia. Respir. Physiol. Neurobiol. 132 (1), 17-41.

Gonzalez, C., Agapito, M.T., Rocher, A., Obeso, A., 2003. Biology of reactive oxygen species. Their role in oxygen chemoreception in the carotid body. In: Lahiri, S., Semenza, G., Prabhakar, N. (Eds.), Oxygen Sensing: Responses and Adaptations to Hypoxia. Marcel Dekker, Inc., NY (USA), pp. 489-505.

Gonzalez, C., Sanz-Alfayate, G., Obeso, A., Agapito, M.T., 2004. Role of glutathione redox state in oxygen sensing by carotid body chemoreceptor cells. Methods Enzymol. 381, 40-71.

Gonzalez-Martín, M.C., Vega-Agapito, M.V., Agapito, M.T., Obeso, A., Gonzalez, C., 2007. Do reactive oxygen species participate in acclimatization to hypoxia? In: Lung Science Conference, Taormina, Sicily, Italy.

Gredilla, R., Barja, G., Lopez-Torres, M., 2001. Effect of short-term caloric restriction on $\mathrm{H}_{2} \mathrm{O}_{2}$ production and oxidative DNA damage in rat liver mitochondria and location of the free radical source. J. Bioenerg. Biomembr. 33 , 279-287.

Gryglewski, R.J., Palmer, R.M., Moncada, S., 1986. Superoxide anion is involved in the breakdown of endothelium-derived vascular relaxing factor. Nature 320, 454-456.

Halliwell, B., Gutteridge, J.M.C., 1999. Free Radicals in Biology and Medicine, third ed. Oxford University Press, Oxford, UK.

Han, D., Canali, R., Garcia, J., Aguilera, R., Gallaher, T.K., Cadenas, E., 2005. Sites and mechanisms of aconitase inactivation by peroxynitrite: modulation by citrate and glutathione. Biochemistry 44, 11986-11996.

Harrison, D.G., 1994. Endothelial dysfunction in atherosclerosis. Basic Res. Cardiol. 89 (Suppl. 1), 87-102.

He, L., Dinger, B., Gonzalez, C., Sander, K., Hoidal, J., Fidone, S., 2004 Hypoxia-induced activation of NADPH oxidase in rat carotid body type I cell. Soc. For. Neurosci. Abts.

He, L., Dinger, B., Sanders, K., Hoidal, J., Obeso, A., Fidone, S., Gonzalez, C., 2005. Effect of $\mathrm{p} 47^{\text {phox }}$ gene-deletion on reactive oxygen species (ROS) production and oxygen sensing in mouse carotid body chemoreceptor cells. Am. J. Physiol. Lung Cell Mol. Physiol. 289, L916-L924.

Hockberger, P.E., Skimina, T.A., Centonze, V.E., Lavin, C., Chu, S., Dadras, S., Reddy, J.K., White, J.G., 1999. Activation of flavin-containing oxidases underlies light-induced production of $\mathrm{H}_{2} \mathrm{O}_{2}$ in mammalian cells. Proc. Natl. Acad. Sci. USA 96, 6255-6260.

Horrigan, F.T., Heinemann, S.H., Hoshi, T., 2005. Heme regulates allosteric activation of the Slo1 BK channel. J. Gen. Physiol. 126, 7-21.

Ischiropoulos, H., Gow, A., Thom, S.R., Kooy, N.W., Royall, J.A., Crow, J.P., 1999. Detection of reactive nitrogen species using 2,7-dichlorodihydrofluorescein and dihydrorhodamine 123. Methods Enzymol. 301, 367-373.

Kacimi, R., Chentoufi, J., Honbo, N., Long, C.S., Karliner, J.S., 2000. Hypoxia differentially regulates stress proteins in cultured cardiomyocytes: role of the p38 stress-activated kinase signaling cascade, and relation to cytoprotection. Cardiovasc. Res. 46, 139-150.

Kemp, P.J., Williams, S.E., Mason, H.S., Wootton, P., Iles, D.E., Riccardi, D., Peers, C., 2006. Functional proteomics of BK potassium channels: defining the acute oxygen sensor. Novartis Found Symp. 272, 141-151.

Kevin, L.G., Camara, A.K., Riess, M.L., Novalija, E., Stowe, D.F., 2003. Ischemic preconditioning alters real-time measure of $\mathrm{O}_{2}$ radicals in intact hearts with ischemia and reperfusion. Am. J. Physiol. Heart Circ. Physiol. 284, H566-H574.

Kumar, G.K., Rai, V., Sharma, S.D., Ramakrishnan, D.P., Peng, Y.J., Souvannakitti, D., Prabhakar, N.R., 2006. Chronic intermittent hypoxia induces hypoxia-evoked catecholamine efflux in adult rat adrenal medulla via oxidative stress. J. Physiol. 575 (Pt 1), 229-239.

Kussmaul, L., Hirst, J., 2006. The mechanism of superoxide production by NADH:ubiquinone oxidoreductase (complex I) from bovine heart mitochondria. Proc. Natl. Acad. Sci. USA 103 (20), 7607-7612.

Kvam, E., Hejmadi, V., Ryter, S., Pourzand, C., Tyrrell, R.M., 2000. Heme oxygenase activity causes transient hypersensitivity to oxidative ultraviolet A radiation that depends on release of iron from heme. Free Radic. Biol. Med. 28, 1191-1196.

Lee, Y.M., Kim, B.J., Chun, Y.S., So, I., Choi, H., Kim, M.S., Park, J.W., 2006. NOX4 as an oxygen sensor to regulate TASK-1 activity. Cell Signal. 18 (4), 499-507.

Leto, T.L., Geiszt, M., 2006. Role of Nox family NADPH oxidases in host defense. Antioxid. Redox Signal. 8 (9-10), 1549-1561.

Linden, D.J., Narasimhan, K., Gurfel, D., 1993. Protoporphyrins modulate voltage gated $\mathrm{Ca}^{2+}$ current in AtT-20 pituitary cells. J. Neurophysiol. 70, 2673-2677.

Lopez-Lopez, J.R., Gonzalez, C., 1992. Time course of $\mathrm{K}^{+}$current inhibition by low oxygen in chemoreceptors cells of adult rabbit carotid body. Effects of carbon monoxide. FEBS Lett. 299, 251-254.

Mancuso, C., Bonsignore, A., Di Stasio, E., Mordente, A., Motterlini, R., 2003. Bilirubin and $S$-nitrosothiols interaction: evidence for a possible role of bilirubin as a scavenger of nitric oxide. Biochem. Pharmacol. 66 (12), 2355-2363

McCartney, C.E., McClafferty, H., Huibant, J.M., Rowan, E.G., Shipston, M.J., Rowe, I.C., 2005. A cysteine-rich motif confers hypoxia sensitivity to mammalian large conductance voltage- and Ca-activated $\mathrm{K}$ (BK) channel alpha-subunits. Proc. Natl. Acad. Sci. USA 102, 1787017876.

Moxness, M.S., Brunauer, L.S., Huestis, W.H., 1996. Hemoblogin oxidation products extract phospholipids from the membrane of human erythrocytes. Biochemistry 35, 7181-7187.

Muller, F.L., Liu, Y., Van Remmen, H., 2004. Complex III releases superoxide to both sides of the inner mitochondrial membrane. J. Biol. Chem. 279 (47), 49064-49073.

Nohl, H., Gille, L., Staniek, K., 2005. Intracellular generation of reactive oxygen species by mitochondria. Biochem. Pharmacol. 69 (5), 719-723.

Noriega, G.O., Gonzales, S., Tomaro, M.L., Batlle, A.M., 2002. Paraquatgenerated oxidative stress in rat liver induces heme oxygenase- 1 and aminolevulinic acid synthase. Free Radic. Res. 36 (6), 633-639.

Obeso, A., Almaraz, L., Gonzalez, C., 1989. Effects of cyanide and uncouplers on chemoreceptor activity and ATP content of the cat carotid body. Brain Res. 481, 250-257.

Obeso, A., Rocher, A., Herreros, B., Gonzalez, C., 1997. Oxygen consumption and energy metabolism of the carotid body. In: Gonzalez, C. (Ed.), The Carotid Body Chemoreceptors. Springer-Verlag, NY, pp. 31-45.

Obeso, A., Gomez-Niño, A., Agapito, M.T., Gonzalez, C., 2006. Mitochondrial ROS, cellular ATP levels and carotid body chemoreceptor cell activation. Physiol. Minirev. 2, 172-173.

Ohashi, T., Mizutani, A., Murakami, A., Kojo, S., Ishii, T., Taketani, S., 2002. Rapid oxidation of dichlorodihydrofluorescin with heme and hemoproteins: formation of the fluorescein is independent of the generation of reactive oxygen species. FEBS Lett. 511, 21-27.

Ohnishi, S.T., Ohnishi, T., Muranaka, S., Fujita, H., Kimura, H., Uemura, K., Yoshida, K., Utsumi, K., 2005. A possible site of superoxide generation in the complex I segment of rat heart mitochondria. J. Bioenerg. Biomembr. 37 (1), $1-15$ 
Ortega-Saenz, P., Pascual, A., Gomez-Diaz, R., Lopez-Barneo, J., 2006. Acute oxygen sensing in heme oxygenase-2 null mice. J. Gen. Physiol. 128 (4), 405-411.

Otsubo, T., Yamaguchi, S., Okumura, M., Shirahata, M., 2006. Differential expression of oxygen sensitivity in voltage-dependent $\mathrm{K}$ channels in inbred strains of mice. Adv. Exp. Med. Biol. 580, 209-214.

Pattison, D.I., Davies, M.J., 2006. Actions of ultraviolet light on cellular structures. EXS 96, 131-157.

Perez-Garcia, M.T., Lopez-Lopez, J.R., Gonzalez, C., 1999. Kvbeta1.2 subunit coexpression in HEK293 cells confers O2 sensitivity to kv4.2 but not to Shaker channels. J. Gen. Physiol. 113, 897-907.

Perez-Garcia, M.T., Colinas, O., Miguel-Velado, E., Moreno-Dominguez, A., Lopez-Lopez, J.R., 2004. Characterization of the Kv channels of mouse carotid body chemoreceptor cells and their role in oxygen sensing. J. Physiol. 557 (Pt 2), 457-471.

Prabhakar, N.R., 1998. Endogenous carbon monoxide in control of respiration. Respir. Physiol. 114 (1), 57-64.

Prabhakar, N.R., Dinerman, J.L., Agani, F.H., Snyder, S.H., 1995. Carbon monoxide: a role in carotid body chemoreception. Proc. Natl. Acad. Sci. USA 92, 1994-1997.

Riesco-Fagundo, A., Pérez-García, M.T., Gonzalez, C., López-López, J.R., 2001. $\mathrm{O}_{2}$ modulates large-conductance $\mathrm{Ca}^{2+}$-dependent $\mathrm{K}^{+}$channels of rat chemoreceptor cells by a membrane-restricted and $\mathrm{CO}$-sensitive mechanism. Circ. Res. 89, 430-436.

Rifkind, J.M., Zhang, L., Levy, A., Manoharan, P.T., 1991. The hypoxic stress on erythrocytes associated with superoxide formation. Free Radic. Res. Commun. 12/13, 645-652.

Ryter, S.W., Alam, J., Choi, A.M., 2006. Heme oxygenase-1/carbon monoxide: from basic science to therapeutic applications. Physiol Rev. 86 (2), 583-650.

Sanchez, D., Ganfornina, M.D., López-López, J.R., Obeso, A., Pérez-García, M.T., Sanz-Alfayate, G., González, G., 2002. Molecular identification of Kvalpha subunits that contribute to the oxygen-sensitive $\mathrm{K}(+)$ current of chemoreceptor cells of the rabbit carotid body. J. Physiol. 542, 369-382.

Sanders, K.M., Koh, S.D., 2006. Two-pore-domain potassium channels in smooth muscles: new components of myogenic regulation. J. Physiol. 570 (Pt 1), 37-43.

Schafer, F.Q., Buettner, G.R., 2001. Redox environment of the cell as viewed through the redox state of the glutathione disulfide/glutathione couple. Free Radic. Biol. Med. 30, 1191-1212.

Sedlak, T.W., Snyder, S.H., 2004. Bilirubin benefits: cellular protection by a biliverdin reductase antioxidant cycle. Pediatrics 113 (6), 1776-1782.
Sharma, R., Awasthi, S., Zimniak, P., Awasthi, Y.C., 2000. Transport of glutathione-conjugates in human erythrocytes. Acta Biochim. Pol. 47, 751-762.

Sipos, I., Tretter, L., Adam-Vizi, V., 2003. The production of reactive oxygen species in intact isolated nerve terminals is independent of the mitochondrial membrane potential. Neurochem. Res. 28 (10), 1575-1581.

Summers, B.A., Overholt, J.L., Prabhakar, N.R., 1999. Nitric oxide inhibits L-type $\mathrm{Ca}^{2+}$ current in glomus cells of the rabbit carotid body via a cGMPindependent mechanism. J. Neurophysiol. 81 (4), 1449-1457.

Tang, X.D., Xu, R., Reynolds, M.F., Garcia, M.L., Heinemann, S.H., Hoshi, T., 2003. Haem can bind to and inhibit mammalian calcium-dependent Slo1 BK channels. Nature 425, 531-535.

Toninello, A., Salvi, M., Pietrangeli, P., Mondovi, B., 2004. Biogenic amines and apoptosis: minireview article. Amino Acids 26 (4), 339-343.

Turrens, J.F., 2003. Mitochondrial formation of reactive oxygen species. J. Physiol. 552 (Pt 2), 335-344.

Votyakova, T.V., Reynolds, I.J., 2001. DeltaPsi(m)-dependent and -independent production of reactive oxygen species by rat brain mitochondria. J. Neurochem. 79 (2), 266-277.

Waypa, G.B., Schumacker, P.T., 2006. Role for mitochondrial reactive oxygen species in hypoxic pulmonary vasoconstriction. Novartis Found Symp. 272, 176-192.

Williams, S.E., Wootton, P., Mason, H.S., Bould, J., Iles, D.E., Riccardi, D., Peers, C., Kemp, P.J., 2004. Hemoxygenase-2 is an oxygen sensor for a calcium-sensitive potassium channel. Science 306 (5704), 2093-2097.

Wu, L., Wang, R., 2005. Carbon monoxide: endogenous production, physiological functions, and pharmacological applications. Pharmacol. Rev. 57 (4), 585-630.

Xi, Q., Tcheranova, D., Parfenova, H., Horowitz, B., Leffler, C.W., Jaggar, J.H., 2004. Carbon monoxide activates KCa channels in newborn arteriole smooth muscle cells by increasing apparent $\mathrm{Ca}^{2-}$ sensitivity of alpha-subunits. Am. J. Physiol. Heart Circ. Physiol. 286, H610-H618.

Young, T.A., Cunningham, C.C., Bailey, S.M., 2002. Reactive oxygen species production by the mitochondrial respiratory chain in isolated rat hepatocytes and liver mitochondria: studies using myxothiazol. Arch. Biochem. Biophys. 405 (1), 65-72.

Zhang, Y., Furuyama, K., Adachi, T., Ishikawa, K., Matsumoto, H., Masuda, T., Ogawa, K., Takeda, K., Yoshizawa, M., Ogawa, H., Maruyama, Y., Hida, W., Shibahara, S., 2006. Hypoxemia and attenuated hypoxic ventilatory responses in mice lacking heme oxygenase-2: evidence for a novel role of heme oxygenase- 2 as an oxygen sensor. Adv. Exp. Med. Biol. 580, 161-166. 